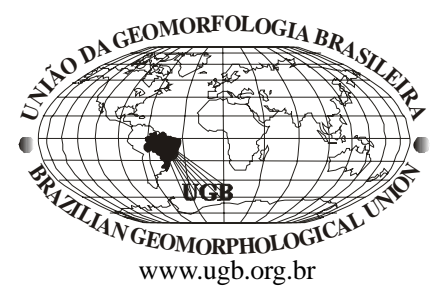

\title{
DELIMITAÇÃO AUTOMÁTICA DE BACIAS DE DRENAGENS E ANÁLISE MULTIVARIADA DE ATRIBUTOS MORFOMÉTRICOS USANDO MODELO DIGITAL DE ELEVAÇÃO HIDROLOGICAMENTE CORRIGIDO
}

\author{
Sandro Nunes de Oliveira \\ Departamento de Geografia da Universidade de Brasília (UnB) \\ sandronunes@unb.br \\ Osmar Abílio de Carvalho Júnior \\ Departamento de Geografia da Universidade de Brasília (UnB) \\ osmarjr@unb.br \\ Telma Mendes da Silva \\ Departamento de Geografia - Universidade Federal do Rio de Janeiro \\ telmendes@globo.com \\ Roberto Arnaldo Trancoso Gomes \\ Departamento de Geografia da Universidade de Brasília (UnB) \\ robertogomes@unb.br \\ Éder de Souza Martins \\ EMBRAPA Cerrados \\ eder@cpac.embrapa.br \\ Renato Fontes Guimarães \\ Departamento de Geografia da Universidade de Brasília (UnB) \\ renatofg@unb.br \\ Nilton Correia da Silva \\ Centro Universitário de Anápolis \\ nilton@unievangelica.edu.br
}

\begin{abstract}
Resumo
A topologia e geometria das redes de drenagem têm contribuído substancialmente para os estudos em geomorfologia e hidrologia, incluindo modernos modelos de evolução da paisagem. Este trabalho tem como objetivo apresentar uma metodologia para extração automatizada de bacias e sub-bacias de drenagem e calcular seus atributos morfométricos agrupando-as pelas similaridades. A metodologia pode ser dividida nas seguintes etapas: (a) construção do Modelo Digital de Elevação (MDE) hidrologicamente corrigido, (b) delimitação das bacias de drenagem a partir do MDE considerando a hierarquização de bacias de drenagem proposta por Strahler, (c) cálculo dos atributos morfométricos das bacias de drenagem e (d) análise estatística multivariada (análise de grupos e análise de componentes principais). Neste trabalho são apresentados algoritmos para a
\end{abstract}


extração da rede de drenagem e dos limites de bacias a partir do MDE como também muitos problemas pertinentes. A preparação do MDE incluiu o preenchimento de depressões, introdução da drenagem e o cálculo da direção de fluxo e grade de acumulação de fluxo. A análise de componentes principais reduziu os atributos morfométricos da bacia de drenagem em três fatores, com alta porcentagem da variância original. A partir da análise de grupos definiram-se sete classes de bacias com padrões morfológicos típicos. Os resultados obtidos sugerem a viabilidade de aplicação da mesma seqüência de procedimentos para outras áreas.

Palavras-chave: Bacia de drenagem; Modelo Digital de Elevação; Análise de Grupos; Principal Component Analysis, Morfometria.

\begin{abstract}
:
The topology and geometry of the drainage networks have contributed substantially to geomorphology and hydrology studies, including modern concepts of landscape evolution. This work aims at presenting a methodology for automated extraction of drainage basins and sub-basins, calculating their morphometric attributes and grouping them in accordance to their similarities. The methodology can be subdivided into four stages: (a) elaboration of the hydrologically corrected DEM; (b) delimitation catchment boundaries from digital elevation model (DEM) according to Strahler's drainage network order; (c) determination of the drainage-basin morphometric attributes, and (d) multivariate analysis (factor analysis and cluster analysis). In this paper algorithms for drainage network extraction and catchment boundaries from DEMs, as well as their most pertinent problems, are presented. The DEM preparation included pit filling, stream burning and the calculation of flow direction and flow accumulation grids. The Principal Component Analysis reduced the morphometric attributes of the drainage basins in three factors, with high percentage of the original variance. Cluster analysis defined seven classes of basins with typical morphological patterns. The results suggest that it is viable to apply the same sequence of procedures in other geographic areas.
\end{abstract}

Keywords: Watersheds; Digital elevation model; Cluster Analysis; Análise de Componentes Principais; Morphometry.

\section{Introdução}

As bacias de drenagem constituem unidades territoriais de planejamento que podem ser tratadas como um sistema onde há entradas, saídas e transformações. Desta forma, os modelos de gerenciamento dos recursos hídricos assumem a bacia hidrográfica como unidade geográfica de referência ou de intervenção, uma vez que nela ocorre boa parte das relações de causa e efeito que envolvem o meio ambiente. Esse conceito está presente na Lei 9.433 de 9 de janeiro de 1997, que instituiu a Política Nacional de Recursos Hídricos, que define a "Bacia Hidrográfica" como "unidade territorial” para a operacionalização do Sistema Nacional de Gerenciamento de Recursos Hídricos (Brasil, 1997).

Neste propósito, proliferam-se órgãos e associações para a gestão da água em bacias de drenagem com o escopo de estabelecer a capacidade, disponibilidade e possibilidade de crescimento e exploração. A demanda crescente de água necessita de uma análise que considere o balanço hídrico e a renovação do sistema natural. Dentro dessa perspectiva, o gerenciamento de bacias de drenagem é um instrumento que orienta o poder público e a sociedade, no longo prazo, na utilização e monitoramento dos recursos naturais, econômicos e sócio-culturais, de forma a promover o desenvolvimento sustentável (Lanna, 1995).
Os estudos de bacia hidrográfica podem ser abordados sob o ponto de vista morfométrico e dinâmico (Pinto et al., 1973; Llamas, 1993; Silveira, 2001). O estudo morfométrico engloba as análises referentes à hierarquia fluvial, análise areal, linear e hipsométrica obtidos de mapas, fotografias aéreas e imagens de satélites que indicam as características físicas da bacia. Os dados da dinâmica de uma bacia de drenagem são obtidos de coletas e medições realizadas no campo e a partir da elaboração de índices estatísticos e modelos matemáticos referentes à precipitação, infiltração, evaporação e evapotranspiração, escoamento superficial, regime dos cursos d’água, água subterrânea e transporte de sedimentos. Muitos estudos analisam informações morfométricas para modelar a dinâmica da bacia de drenagem (Mark, 1983).

Tradicionalmente, os atributos das bacias de drenagem são obtidos manualmente a partir de mapas e trabalhos de campo. No entanto, nas duas últimas décadas as informações hidrográficas têm sido obtidas de Modelos Digitais de Elevação (MDE) e de modelos hidrológicos distribuídos, que permitem uma maior sensibilidade das propriedades espaciais. Esses modelos possibilitam uma melhor simulação de fluxo da água e conseqüentemente uma maior precisão na delimitação das bacias e sub-bacias de drenagem. As principais vantagens do emprego de métodos automatizados 

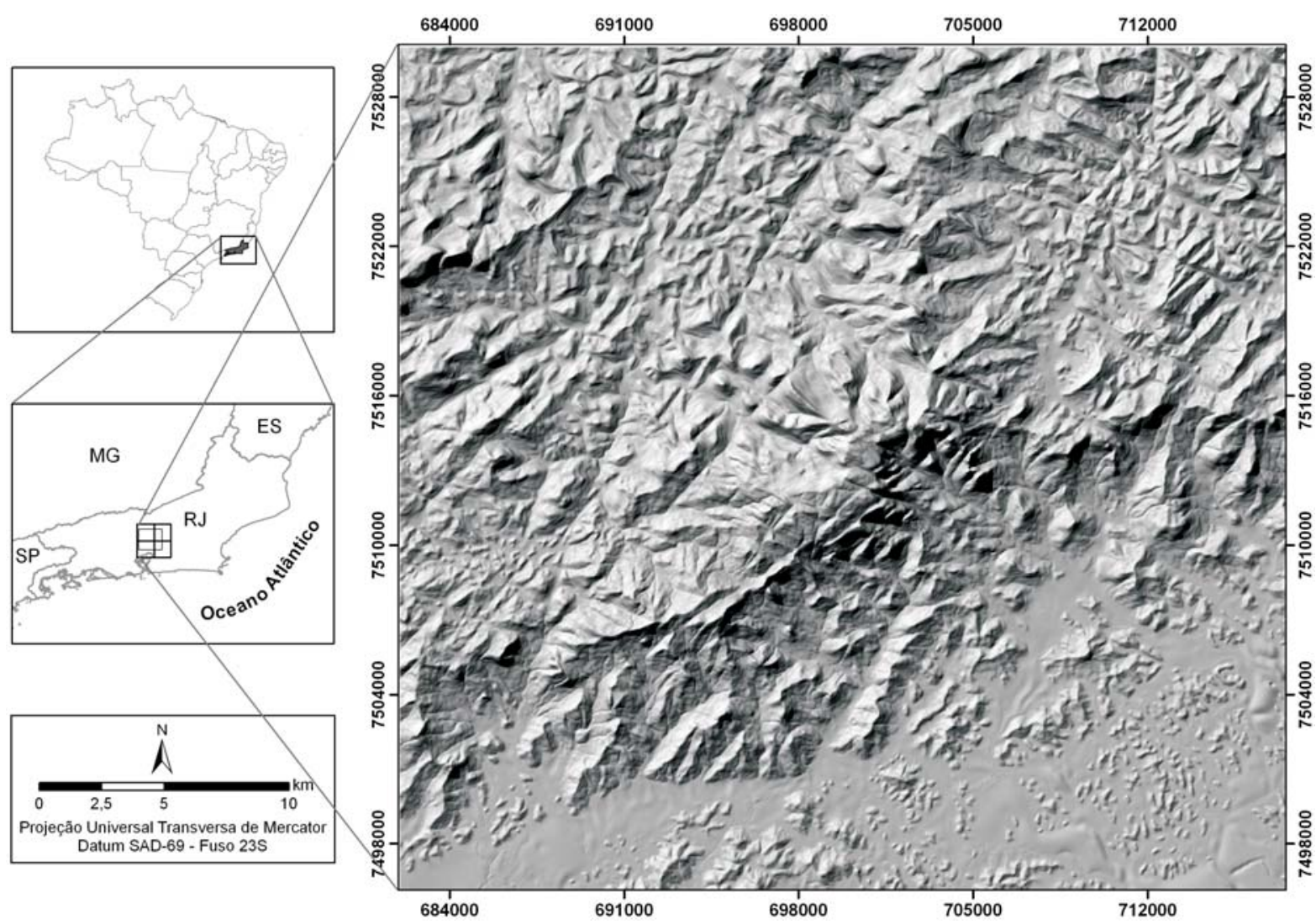

Figura 1 - Localização da área de estudo.

são: rapidez, menor subjetividade e maior facilidade de reprodução do que as técnicas manuais (Tribe, 1992). A delimitação de bacias de drenagem utilizando métodos automatizados exige o emprego de um MDE que descreva de forma mais fidedigna possível a estrutura da rede de drenagem da bacia.

Este trabalho tem como objetivo apresentar uma metodologia para extração automatizada de bacias e subbacias de drenagem e calcular seus atributos morfométricos agrupando-as pelas similaridades.

\section{2. Área de estudo}

A área de estudo está localizada no Estado do Rio de Janeiro entre as coordenadas UTM 7.496.000N - 718.000E e $7.530 .000 \mathrm{~N}-682.000 \mathrm{E}$, sendo coberta pelas seguintes cartas topográficas do IBGE em escala 1:50.000: Itaipava (SF-23-ZB-I-4), Teresópolis (SF-23-Z-B-II-3), Petrópolis (SF-23-Z-BIV-2) e Itaboraí (SF-23-Z-B-V-1) (Figura 1).

O clima é mesotérmico brando superúmido com temperatura média anual de $18^{\circ} \mathrm{C}$ e índice pluviométrico médio de 2.300mm (Nimer, 1977). A Geologia é constituída essencialmente por gnaisses bandados do Complexo Paraíba do Sul, por granitos pós-tectônicos da Suíte Intrusiva da Serra dos Órgãos e por sedimentos aluvionares e litorâneos (Brasil,
1983). A Geomorfologia da área se insere no Domínio Morfoestrutural do Planalto Atlântico e no Domínio das Depressões Tectônicas Mesozóica-Cenozóicas. Esses domínios subdividem-se nas Regiões do Planalto e Escarpas da Serra dos Órgãos e na Região do Rift da Guanabara (Silva, 2003).

O uso e cobertura da terra são constituídos de áreas urbanas, agrícolas, pastagens e áreas de proteção ambiental (Parque Nacional da Serra dos Órgãos e Área de Proteção Ambiental de Petrópolis). Nas áreas de proteção ambiental a vegetação é representada pelas formações florestais e campestres (Alonso, 1977; Martinelli, 1989). Pela classificação de Rizzini (1979) é possível identificarmos quatro fitofisionomias da Mata Atlântica: Floresta Pluvial Baixo Montana, Floresta Pluvial Montana, Floresta Pluvial Alto Montana e Campos de Altitude.

\section{Metodologia}

A metodologia pode ser dividida nas seguintes etapas: (a) construção do Modelo Digital de Elevação (MDE) hidrologicamente corrigido, (b) delimitação das bacias de drenagem; (c) cálculo dos atributos morfométricos das bacias de drenagem e (d) análise estatística multivariada das bacias de drenagem. 


\subsection{MDE hidrologicamente corrigido}

Na geração do MDE utilizou-se a base cartográfica na escala 1:50.000 do IBGE, em formato digital, contendo curvas de nível com eqüidistância de 20 metros, pontos cotados e hidrografia. Esses dados foram corrigidos e posteriormente interpolados pelo módulo TOPOGRID do programa ArcInfo (ESRI, 1998). Na correção das curvas de nível foram conferidos a conectividade, a falta de segmentos de linhas e os valores de altitude. Para as drenagens conferiu-se o lineamento da drenagem em relação às curvas de nível, a conectividade, o tamanho mínimo de segmento de linha e a direção de fluxo. Foram conferidos ainda os valores dos pontos cotados.

A interpolação pelo método TOPOGRID emprega o algoritmo desenvolvido por Hutchinson (1989) que objetiva criar um MDE para estudos hidrológicos. O algoritmo foi elaborado para produzir um acurado MDE que contenha as propriedades das drenagens e os dados de direção de fluxo. Nesse procedimento preserva-se as características hidrográficas, remove-se os dados espúrios relativos a pontos de depressão ou de elevação e utiliza uma técnica de interpolação por diferenças finitas (Hutchinson, 1989). Os valores de altimetria da área de estudo variam de zero, nível do mar, até 2263 metros, nos picos mais altos da Serra, representando suas diferentes unidades geomorfológicas.

Além do procedimento de interpolação para a obtenção de um MDE hidrologicamente corrigido devem ser considerados os seguintes aspectos: (a) eliminação das depressões artificiais, (b) introdução de informações sobre as localizações de rede de drenagem e lagos em regiões planas, e (c) limitações inerentes dos métodos de obtenção da direção de fluxo (Martz \& Garbrecht, 1995; Turcotte et al. 2001).

\subsubsection{Eliminação das Depressões Artificiais}

No MDE as depressões devem ser preenchidas de forma a permitir uma continuidade do fluxo. Algumas depressões são provenientes de erros introduzidos durante o processo de interpolação dos dados, enquanto que outras são feições reais da topografia, tais como as presentes em ambientes cársticos. As depressões artificiais são usualmente concentradas em regiões de inundação ou nas proximidades de determinados tipos de paisagem onde um MDE de baixa resolução não consegue representá-los, tais como nas áreas de múltiplos canais, dunas ou depósitos de sedimentos. Assim, o número de depressões artificiais normalmente é inversamente proporcional a resolução do MDE (Lindsay \& Creed, 2005).

Várias técnicas são propostas para o preenchimento das depressões artificiais. Inicialmente, foram utilizadas técnicas de suavização do terreno, entretanto esses podem provocar um efeito indesejável do aumento das áreas de depressões (O’Callaghan \& Mark, 1984). Um método mais robusto foi desenvolvido por Jenson \& Domingue (1987) que apenas eleva as células contidas dentro das depressões. Esse método é muito divulgado e está implementado no programa ArcInfo (ESRI, 1998) e no programa livre GRASS. Recentemente outros métodos têm sido propostos como: ajuste da elevação da depressão considerando a sua posição na bacia, que objetiva reproduzir um perfil mais natural do canal (Tianqi et al., 2003); utilização de corte do terreno para reforçar o fluxo convergente (Soille et al., 2003) e a adoção de método baseado em processos físicos hidrogeomorfológicos (Grimaldi et al., 2007). Neste trabalho é utilizado o método Jenson \& Domingue (1987).

\subsubsection{Introdução de Informações sobre a Rede de Drenagem e Lagos}

Os diferentes algoritmos de hidrologia, normalmente produzem resultados mais consistentes para áreas de relevo acentuado do que para as mais planas. Assim, o maior esforço tem sido realizado na modelagem de fluxo de água em terrenos quase planos onde os canais são pequenos e sem ou com gradiente muito baixo, o que dificulta a delimitação automática. Desta forma, muitos dos erros na descrição dos canais e subseqüentemente da delimitação das bacias de drenagem são provenientes da falta de informações sobre as localizações da rede de drenagem e lagos. Com o objetivo de minimizar esse problema, soluções são propostas considerando desde pequenas mudanças no valor de altimetria do pixel (Garbrecht \& Martz, 1997; Mackay \& Band, 1998) até a utilização de informações lineares de drenagens como dados complementares ao MDE. Esta última opção permite inferir o caminho da água e obter um modelo mais acurado da estrutura de drenagem e conseqüentemente uma melhor delimitação de sub-bacias (Tarboton, 1997).

Um procedimento para garantir a demarcação da rede de drenagem consiste em aprofundar a hidrografia no MDE, de forma a induzir a direção de fluxo ao longo dos canais. Este procedimento pode ser subdivido nas seguintes etapas: (a) definição da rede de drenagem, (b) operações de álgebras de mapas para o aprofudamento da rede de drenagem no MDE, e (c) cálculo da direção de fluxo.

A etapa de definição da rede de drenagem consiste em gerar uma imagem binária, na qual a largura dos canais de drenagem seja de apenas uma célula. Essa característica facilita, posteriormente, os algoritmos de delimitação automática das sub-bacias. Normalmente, a simples conversão do vetor de drenagem para o formato raster não garante essa propriedade sendo necessário o uso de programas específicos. Dentre os algoritmos disponíveis para a delimitação automática da rede de drenagem pode-se citar o método 
Delimitação automática de bacias de drenagens e análise multivariada de atributos...

TRACEGRID do programa ArcInfo. O TRACEGRID utiliza como dados de entrada: (a) os pontos de nascente para indicar o início da rede de drenagem, e (b) a grade de direção de fluxo, que demonstra o caminho da água na superfície. Uma dificuldade desse processamento é a localização das nascentes (Vogt et al., 2003). Neste trabalho, com o uso do Xtools e do TRACEGID, obteve-se, respectivamente 1108 pontos de nascentes (Figura 2a) e a imagem binária da rede de drenagem (Figura 2b).

$\mathrm{O}$ aprofundamento da hidrografia pode ser obtido a partir de álgebras de mapas considerando o MDE e a grade binária da rede de drenagem. O MDE com o aprofundamento da drenagem pode ser obtido por meio de três operações: (a) multiplicação da grade de hidrografia (área de drenagem com valor um e as demais áreas com valores nulos) com o MDE subtraído do valor do rebaixamento em metros; (b) multiplicação da grade invertida de hidrografia (área de drenagem com valores nulos e as demais áreas com valor um) com o MDE original; e (c) soma das duas grades anteriores (Figura 3). A grade resultante apresenta ao longo das drenagens valores extremamente baixos, em relação às áreas circunvizinhas, gerando artificialmente uma feição de canyon. O valor constante de rebaixamento sugerido é que seja um número que mantenha os dados do MDE positivos, enquanto que a largura seja de uma célula. No caso da imagem resultante apresentar algum valor negativo, deve-se somar um valor, de modo que fique positivo. Para a área de estudo, o rebaixamento da drenagem foi de 30 metros. Devido à existência de áreas com altitudes ao nível do mar, somou-se um valor constante de 50 metros no MDE para manter os valores de altimetria positivos.

Após o aprofundamento da drenagem, com o objetivo de manter a conectividade do fluxo ao longo do canal, realizase o preenchimento das depressões e o cálculo da direção de fluxo. A extração da direção de fluxo, apenas ao longo do canal, é obtida pela divisão da imagem de direção de fluxo com a imagem binária da área da drenagem (Tarboton, 2005) (Figura 4). No cálculo da direção de fluxo foi utilizado o método D8.

A

B
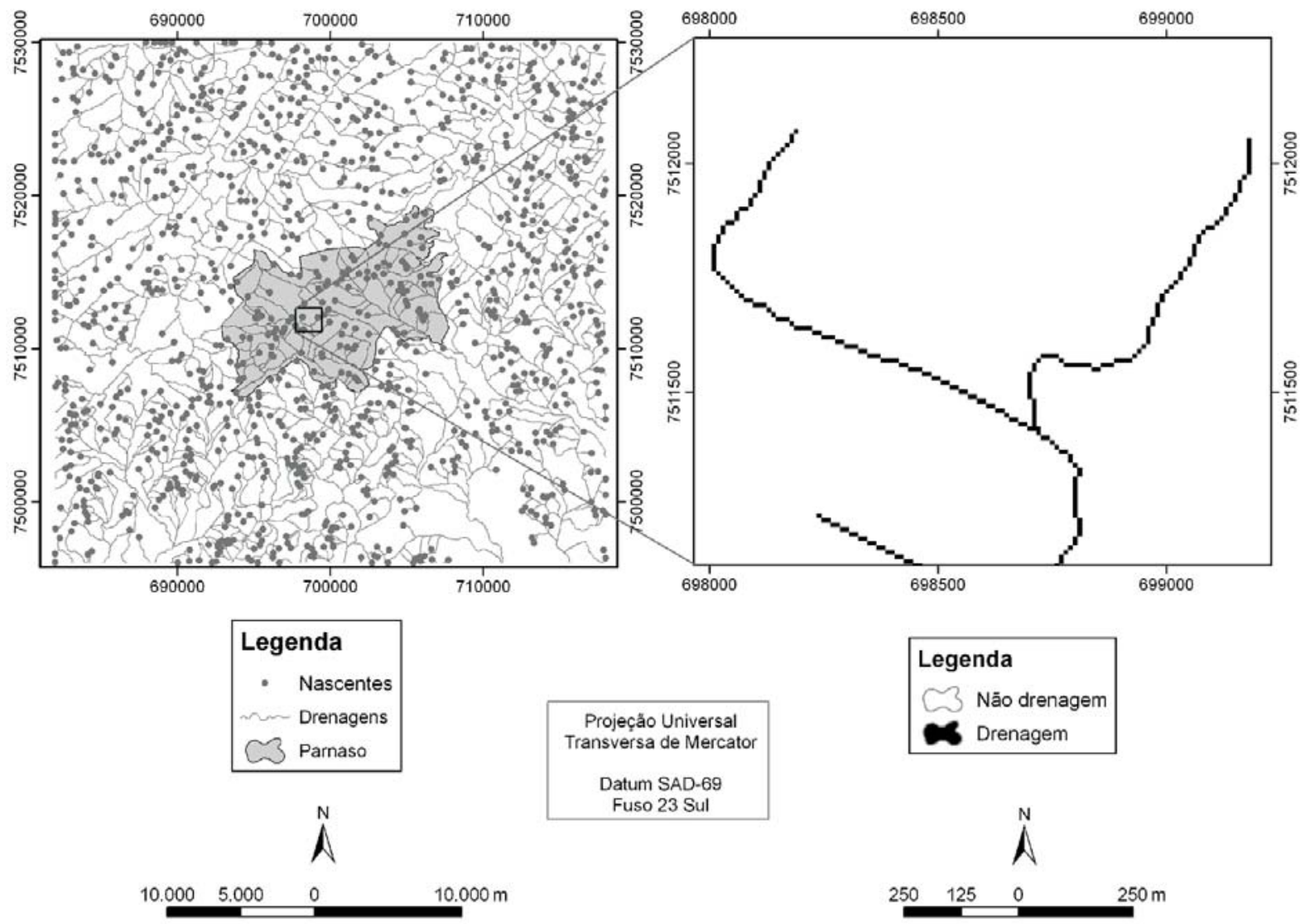

Figura 2 - (A) Pontos de nascentes obtidos a partir das drenagens no formato vetorial. (B) Detalhe da drenagem em formato de grade obtida pelo algoritmo TRACEGRID. 


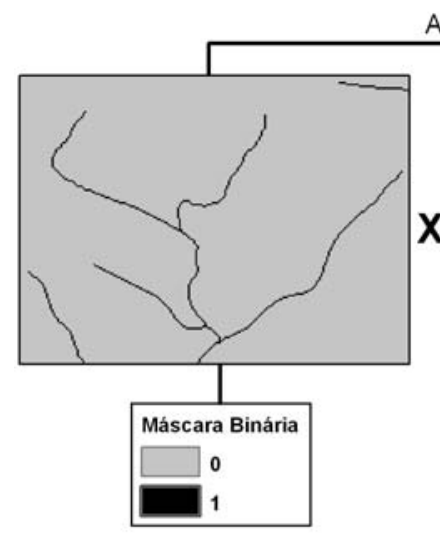

A
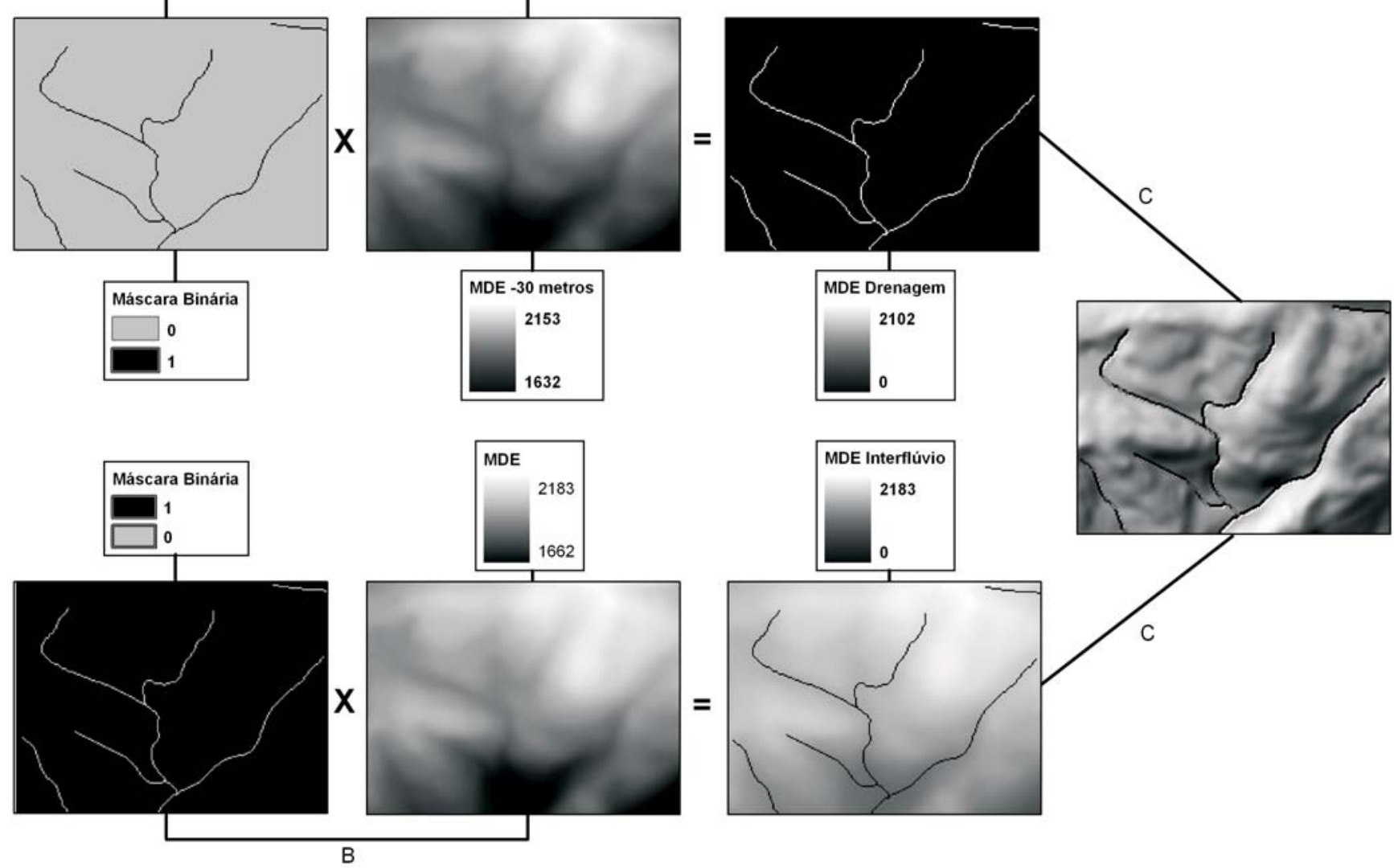

Figura 3 - Procedimentos para o aprofundamento da rede de drenagem (stream burning): (A) multiplicação da máscara binária da hidrografia com o MDE subtraído do valor do rebaixamento; (B) multiplicação da máscara da hidrografia invertida com o MDE original; $e(C)$ soma das duas grades resultantes".

\subsubsection{Direção de Fluxo}

O método D8 é o procedimento mais convencional para a delimitação da estrutura de drenagem. Esse procedimento determina a direção de fluxo de cada célula da grade considerando a maior declividade entre a célula central e as oito células circunvizinhas (E, NE, N, NO, O, SO, S e SE), sendo que o escoamento sempre ocorre para uma dessas oito células (O’Callaghan \& Mark, 1984).

O método D8 mostra-se adequado para zonas de fluxo convergente e ao longo de vales definidos, contudo para outras situações verificam-se erros. Assim, outros métodos são propostos considerando uma direção de fluxo não discreta ou um fluxo em múltipla direção (Tarboton, 1997; CostaCabral \& Burges, 1994; Quinn et al., 1991). Esses métodos, que utilizam fluxos não discretos apresentam, quando comparados com o D8, uma diminuição de erros relativos à direção de fluxo, e, conseqüentemente, uma melhor delimitação do canal (Freeman, 1991; Desmet \& Govers, 1996; Ramos et al., 2003).
No entanto, esses outros métodos apresentam como desvantagem eliminar a relação unimodal entre a direção do fluxo e a rede de drenagem, onde a transferência do fluxo é realizada de pixel para pixel. Portanto, na metodologia de aprofundamento da drenagem, cuja a espessura é de apenas um pixel, o método D8 mostra-se o mais adequado.

Assim, para obter um melhor ajuste do modelo pode-se conjugar o método discreto D8 ao longo dos canais e não discretos, como o método D-infinito proposto por Tarboton (1997), nas demais partes do relevo.

\subsection{Delimitação das bacias de drenagem}

O limite da bacia obedece a parâmetros topográficos, onde se traça uma linha imaginária pelos pontos mais elevados do terreno, atravessando o curso d'água apenas no exutório (Christofoletti, 1980). O exutório pode ser demarcado na confluência de dois cursos d'água ou mesmo considerando outros critérios como, por exemplo, a barragem de uma hidrelétrica ou um ponto de captação de água para consumo em uma cidade. Alguns métodos de delimitação de bacias de 
A

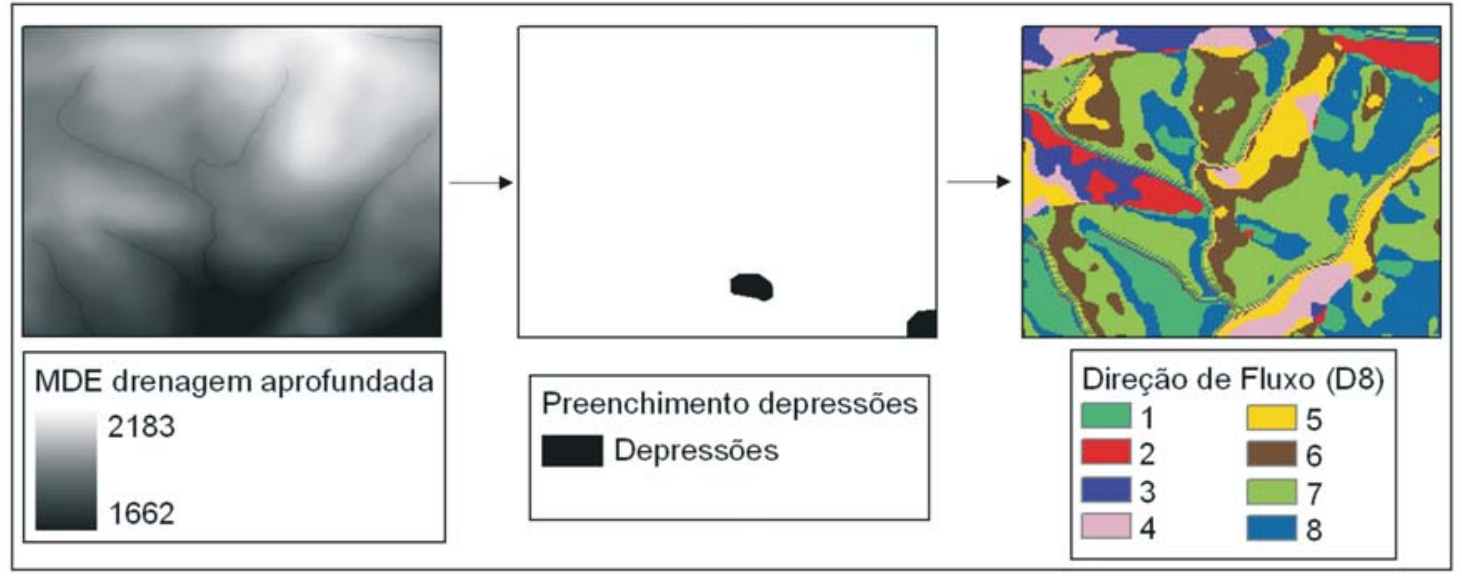

B
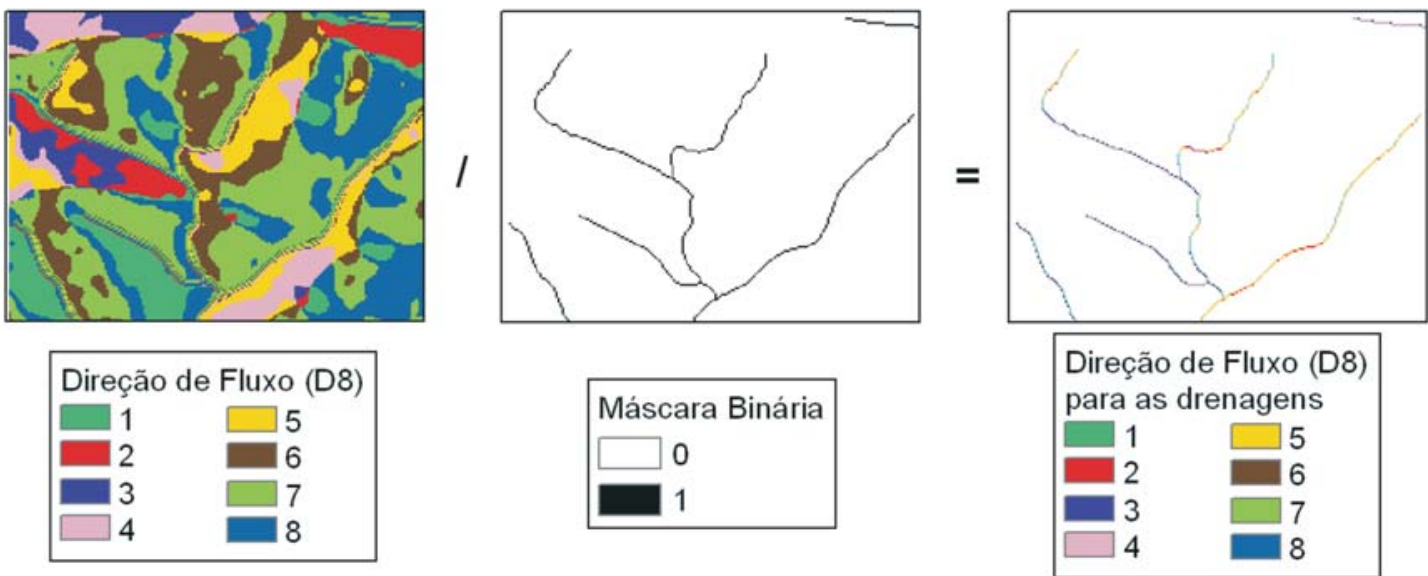

Figura 4 - Procedimentos para a obtenção da direção de fluxo ao longo dos canais de drenagens: (a) preenchimento das depressões do MDE com a drenagem aprofundada e obtenção da direção de fluxo do método D8; (b) divisão da grade de direção de fluxo pela máscara binária resultando na direção de fluxo do método D8 para as drenagens.

drenagem, como o de eqüidistância, não têm um critério geomorfológico. Neste exemplo, o divisor de água se encontra na distância média entre os trechos da rede hidrográfica não avaliando as curvas de nível e pontos cotados. Um aperfeiçoamento para a delimitação das bacias de drenagem é obtido utilizando técnicas computacionais (Martz \& Garbrecht, 1992, 1993; Martz \& De Jong, 1988).

Um importante aspecto na delimitação das sub-bacias é definir o critério de subdivisão. O mais comum computacionalmente consiste na especificação de um tamanho de área (Band, 1986, 1989; Morris \& Heerdegen, 1988; Chorowicz et al., 1992). Esse procedimento, no entanto, é arbitrário e não é padronizado. Uma alternativa é a utilização da hierarquização fluvial, cuja primeira proposição foi o método de Horton (1945). Posteriormente, Strahler (1952) propõe um novo modelo de ordenamento que se torna mais utilizado devido à sua simplicidade e funcionalidade (Smart, 1968). $\mathrm{O}$ método de Strahler (1952) pode ser resumido em quatro pressupostos: (1) canais que originados nas nascentes são definidos como canais de primeira ordem; (2) quando dois canais de ordem " $x$ " se juntam, um canal de ordem " $x+1$ " é criado; (3) quando dois canais de ordem diferentes se juntam o segmento do canal imediatamente à jusante adquire a mais alta ordem entre os dois canais; (4) a ordem da bacia é a mais alta ordem de canal nela existente.

Para a obtenção automática das bacias de drenagem de Strahler pode ser utilizado o algoritmo Terrain Analysis Using Digital Elevation Models - TauDEM (Tarboton, 2005). Neste algoritmo os dados de entrada são o MDE e a grade da direção de fluxo pelo método D8 da rede de drenagem. A partir desses dois atributos o método TauDEM recalcula os demais atributos necessários para a delimitação da bacia, incluindo o 

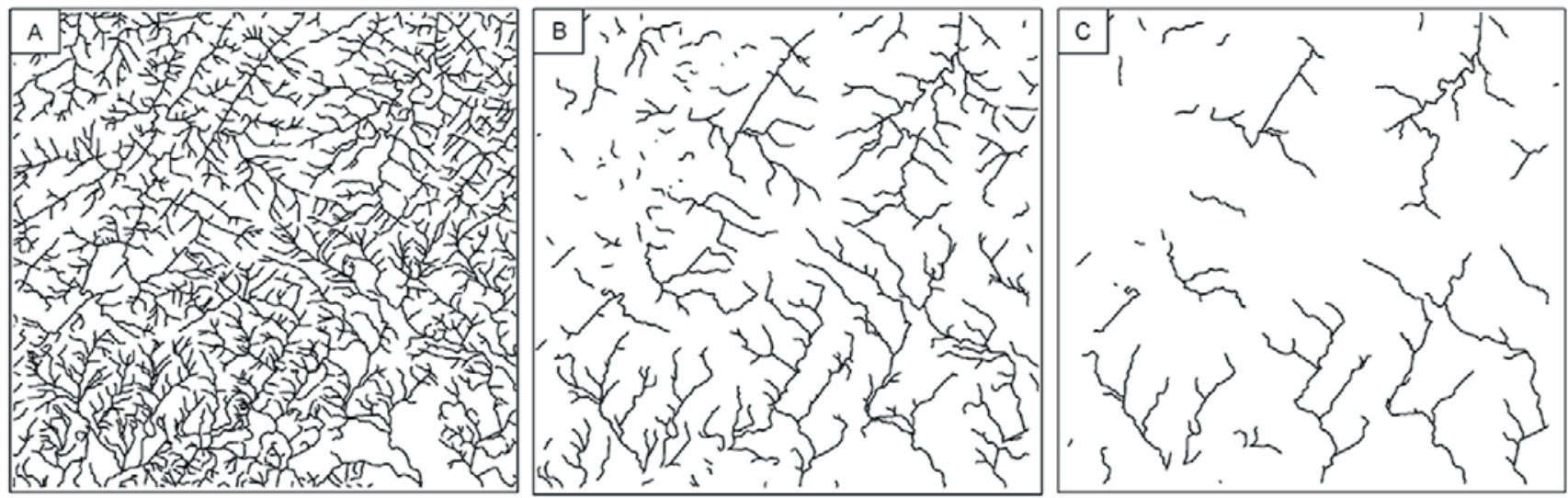

Figura 5 - Segmentos da rede de drenagem obtidos para delimitar as bacias de: $1^{a}$ ordem (A); $2^{a}$ ordem (B) e $3^{a}$ ordem (C).

MDE preenchido e os atributos de terreno obtidos pelo método D8 e D-infinito (declividade, direção de fluxo e área de contribuição). O TauDEM gera para a rede hidrográfica, segmentos de drenagem, conforme a sua respectiva ordem $\left(1^{\text {a }}, 2^{\text {a }}\right.$ e $3^{a}$ ) que são utilizados como base na delimitação das bacias (Figura 5). O algoritmo individualiza tanto as bacias de ordem desejada (Figura 6a) como também fragmentos de bacia demarcados entre o exutório de duas bacias de mesma ordem (Figura 6b).

\subsection{Cálculo dos atributos morfométricos das bacias de drenagem}

A tendência de a superfície organizar-se em bacias de drenagem pode ter como fator dominante o princípio da minimização da energia. A conformação das bacias de drenagem é espacialmente modelada pela difusão e incisão dos processos erosivos, de forma que a perda de energia seja minimizada, tanto no transporte de água como no processo modelador da paisagem (Langbein, 1964; Langbein \& Leopold, 1964; Montgomery \& Dietrich, 1992; RodriguezIturbe et al., 1992a,b). Os dados de morfometria de uma bacia são úteis na análise desses processos.

Desta forma, as variáveis morfométricas das bacias e sub-bacias em diferentes localidades têm sido correlacionadas com fatores e propriedades ambientais (permeabilidade, enchentes, processos de erosão e movimento de massa, substrato rochoso, evolução pedológica, entre outros) (Reddy et al., 2004; Villela \& Mattos, 1975). Essas variáveis também ajudam a entender o processo de ocupação antrópica e auxiliam no planejamento e manejo da bacia (Cardoso et al. 2006; Demattê \& Demétrio, 1995; Mesa, 2006; Souza \& Batista, 2007).

A espacialização das feições morfométricas por unidades de bacia de drenagem pode trazer uma perspectiva integradora dos diversos fatores que atuam sobre o modelado como geologia, clima, fatores antrópicos, entre outros.
Numerosas variáveis foram definidas para a análise e a descrição quantitativa da bacia de drenagem, considerando tanto atributos lineares e areais. Vários índices e razões geométricas também são empregados na descrição dessa unidade ambiental.

Neste trabalho, utilizam-se tanto variáveis básicas referentes à bacia como provenientes de índices. A análise considerou tanto as bacias como também as bacias somadas dos fragmentos, de forma a comparar essas duas representações. Dentre os parâmetros básicos na caracterização das sub-bacias foram utilizados: área (A), perímetro (P), altura máxima e mínima ( $\mathrm{M}, \mathrm{m}$ ) e declividade média (Decl). Além desses, foram utilizadas informações provenientes de índices como amplitude topográfica (AT) e índice de circularidade (IC), como também é sugerido o desvio padrão dos dados de altitude como novo parâmetro.

Algoritmos para a determinação de alguns parâmetros morfométricos utilizados (altitude mínima, máxima, média, amplitude, declividade média e desvio padrão) foram elaborados em linguagem $C$.

\subsubsection{Amplitude Topográfica}

A amplitude topográfica da bacia (AT) consiste na diferença da elevação entre a altitude topográfica máxima (M) em relação à mínima (m), sendo expressa por:

$$
A T=M-m
$$

Essa variável representa o gradiente da bacia de drenagem, e conseqüentemente fornece indicações sobre o padrão de fluxo e a quantidade de sedimentos transportados (Hadley \& Schumm 1961). Meis et al. (1982) e posteriormente Silva (2002; 2005) utilizam a amplitude topográfica como um atributo para a classificação de unidades geomorfológicas da região do Planalto Atlântico do Sudeste do Brasil. Nesses estudos é proposto o uso de bacias de drenagem de até segunda 

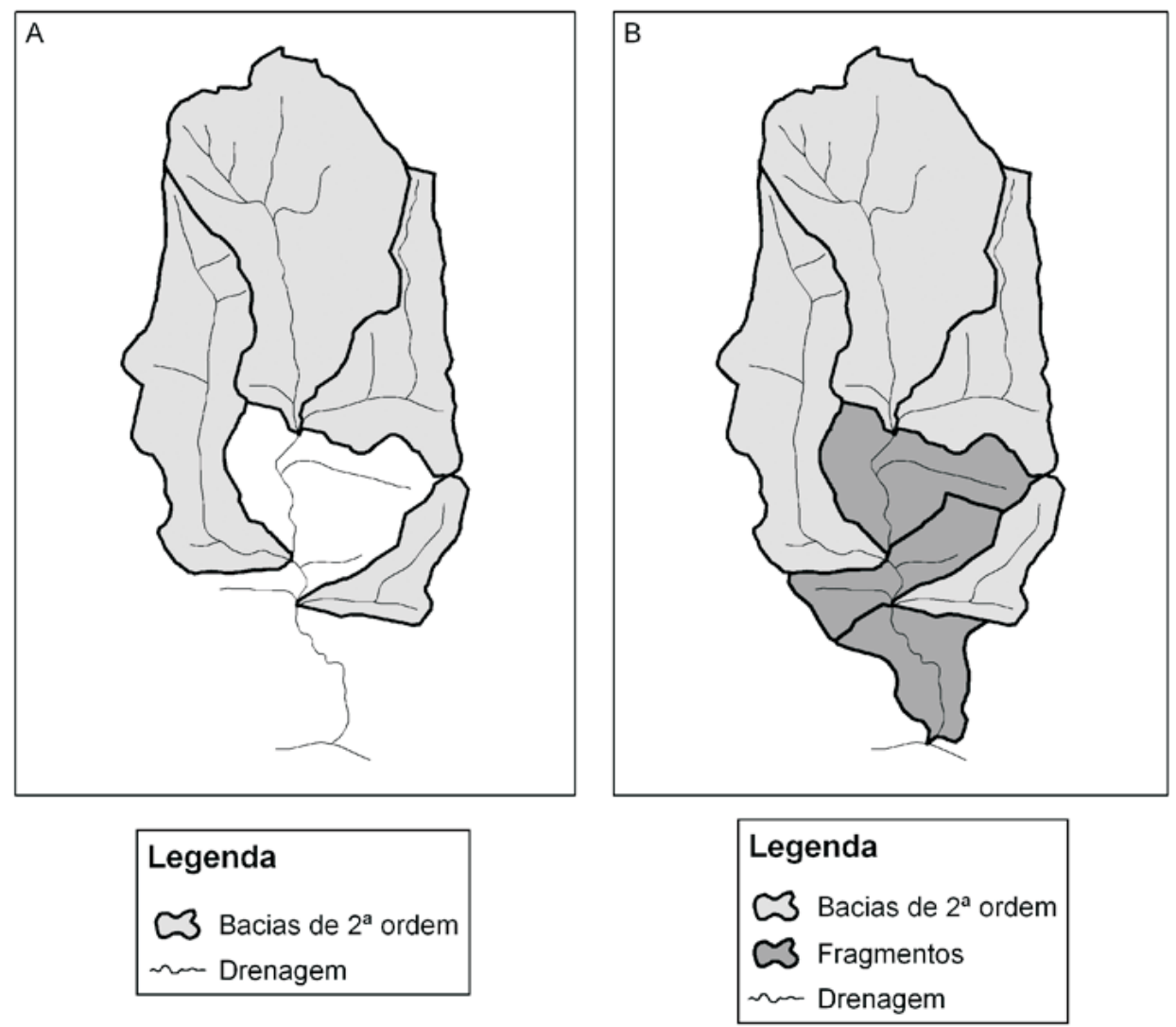

Figura 6 - Bacias de $2^{a}$ ordem da hierarquia de Strahler (A). Bacias de $2^{a}$ ordem da hierarquia de Strahler mais fragmentos (B).

ordem fluvial de Strahler, por estes canais constituírem os de maior poder erosivo das encostas e, portanto, evidenciar padrões gemorfológicos distintos.

\subsubsection{Desvio Padrão dos Dados Altimétricos}

Christofoletti (1980) salienta que uma dificuldade do emprego da amplitude topográfica é uma eventual baixa representatividade areal dos valores extremos. Assim, a altitude máxima pode estar restrita a um ponto excepcional na bacia que encobertaria o real significado da movimentação topográfica. Para evitar essa interferência é proposto no presente trabalho o emprego das medidas de dispersão da altimetria. Esses parâmetros permitem uma melhor caracterização da variação dos dados altimétricos e conseqüentemente uma melhor caracterização do gradiente na bacia. A variância $\left(S^{2}\right)$ mede a dispersão dos dados (valores de altitude $x_{i}$ ) em torno da média $(\bar{X})$ podendo ser expressa como a soma dos quadrados dos desvios dividida pelo número de células me$\operatorname{nos} \operatorname{um}(n-1)$.

$$
s^{2}=\frac{\sum_{i=1}^{n}\left(x_{i}-\bar{x}\right)^{2}}{n-1}
$$

O desvio padrão é a raiz quadrada da variância, possuindo como vantagem apresentar uma unidade de medida igual à dos dados de entrada. No programa elaborado neste trabalho foi desenvolvido um módulo que calcula a altimetria máxima e mínima, amplitude, variância e desvio padrão altimétricos. Este módulo utiliza como informações de entrada a grade dos limites das bacias de drenagem e o MDE.

\subsection{3. Índice de Circularidade}

O índice de circularidade (IC) é a razão entre a área da bacia (A) e a área de um círculo com o mesmo perímetro da bacia (P) (Miller, 1953; Strahler, 1964), sendo expresso por:

$$
I C=\frac{4 \pi A}{p^{2}}
$$

Em que "IC" é a circularidade da bacia, "P” é o perímetro da bacia e "A” é a área da bacia. Nesta formulação o valor máximo é igual a 1 (um), quando corresponde a uma bacia com forma circular ideal. Desta forma, quanto mais próximo de 1 (um) for o valor, maior circularidade possui a bacia. A circularidade da bacia apresenta influência direta na distribuição do hidrograma de vazão no exutório da bacia. 
Em um evento de chuva, as bacias com formato alongado apresentam fluxos de água que atingem o exutório em diferentes tempos conforme o seu posicionamento na bacia. Assim, os fluxos iniciados nas cabeceiras da bacia percorrem um caminho mais longo até o exutório, levando um tempo maior do que aqueles das nascentes próximas do exutório. O formato dos hidrogramas dessas bacias apresenta uma forma achatada. Em contraposição, em uma bacia circular todas as nascentes ficam aproximadamente eqüidistantes do exutório, o que faz com que este seja atingido concomitantemente pelos fluxos, provocando um pico no hidrograma.

\subsection{Análise estatística multivariada dos atributos das bacias de drenagem}

Para realizar uma investigação das inter-relações entre as bacias de drenagem devem ser adotados procedimentos estatísticos multivariados devido ao volume de dados gerados. As técnicas de análise multivariada permitem simplificar e organizar o montante de dados levantados. Dentre os métodos aplicados no estudo de morfometria de bacias de drenagem destacam-se a análise de grupos e a análise de componentes principais (ACP) (Mather \& Doornkamp, 1970).

A Análise de Grupos vem sendo cada vez mais empregada como uma poderosa ferramenta na formulação de sistemas de classificação. Este método estatístico favorece a formulação de hipóteses sobre a estrutura da distribuição interna dos dados. Desta forma, a análise de grupos tem como propósito particionar um conjunto de $\mathrm{N}$ entidades (no nosso caso os dados morfométricos) em subconjuntos distintos e não vazios, que sejam tão homogêneos quanto possível. A classificação dos grupos é definida por intermédio de uma medida de similaridade ou dissimilaridade, como por exemplo, o coeficiente de correlação ou a distância Euclidiana.

Os métodos de análise de grupamento podem ser subdivididos em métodos hierárquicos e não-hierárquicos (Hair et al., 1987). Os procedimentos hierárquicos geram estruturas do tipo árvore, nas quais inicialmente cada elemento é um grupo e a cada passo, os dois grupos mais próximos são agrupados. As metodologias hierárquicas têm como limitação o maior tempo computacional despendido com o aumento do número de amostras e parâmetros.

Os métodos não hierárquicos são apropriados para a classificação de conjuntos de elementos superiores a 1000 pela capacidade computacional. Nesse procedimento, primeiramente, são selecionados centros para os agrupamentos denominados sementes que, a partir de uma distância pré-determinada, agrupam os elementos em sua volta. Dentre os procedimentos não hierárquicos, o método mais comumente usado é o K-médias.
Neste trabalho foi utilizado o método K-médias para as bacias de $1^{\text {a }}, 2^{\text {a }}$ e $3^{\text {a }}$ ordem. Tendo em vista a variação dos valores dos atributos morfométricos os dados foram normalizados pela amplitude. Desta forma, todos os atributos passaram a variar entre zero e um.

A ACP pode ser sumarizada em três passos (Richards, 1986): derivação da matriz de correlação ou de variânciacovariância, (b) cálculo dos autovetores e autovalores, e (c) transformação linear do conjunto de dados. AACP estabelece um novo sistema de coordenadas, no qual os novos eixos maximizam a variabilidade dos dados. Assim, na nova projeção a maior variabilidade repousa no primeiro eixo, a segunda maior no segundo eixo e assim sucessivamente. Esse método transforma o conjunto de variáveis por uma combinação linear em atributos descorrelacionados e ordenados de forma a reduzir a variabilidade. A redução da dimensionalidade permite uma descrição compacta e otimizada do conjunto de dados. Como os eixos são ortogonais entre si não existe informação redundante.

\section{Resultados}

\subsection{Bacias de drenagem e morfometria}

O método utilizado na delimitação automática das bacias de drenagem individualizou para a área de estudo aquelas de $1^{\text {a }}$ ordem fluvial (816 bacias e 1587 bacias mais fragmentos); $2^{\mathrm{a}}$ ordem fluvial (195 bacias e 425 bacias mais fragmentos) e $3^{\text {a }}$ ordem fluvial (63 bacias e 105 bacias mais fragmentos) (Figura 7). O estudo considerando as bacias de diferentes ordens fluviais permite uma análise escalar, possibilitando verificar mudanças de padrões desde a escala local até regional. Os atributos morfométricos analisados foram altimetria mínima, máxima e média, amplitude topográfica, desvio padrão, declividade média, área, perímetro e índice de circularidade. A forma espacial e o agrupamento dos dados da área de estudo apresentam uma orientação preferencial das bacias nas direções NNW e SSE (Figura 7).

Os dados morfométricos das bacias de drenagem altimetria mínima, máxima e média demonstram uma alta correlação entre si para as ordens fluviais analisadas (Figura 8 e Tabelas 1, 2 e 3). Nas bacias de $3^{\text {a }}$ ordem esses atributos permitem individualizar dois segmentos: um referente a faixa litorânea e outro às áreas continentais, onde o limite é demarcado pelo divisor de águas da Serra do Mar com direção WSW-ENE. Com a diminuição da ordem fluvial surgem outros agrupamentos de bacias, como a área central, correspondente ao topo da Serra dos Órgãos e a faixa da escarpa.

As variáveis morfométricas referentes à amplitude, desvio padrão e declividade média salientam as características de variação interna da altimetria e possuem uma alta correlação entre si para todas as ordens fluviais (Figura 9 e Tabelas 1, 2 

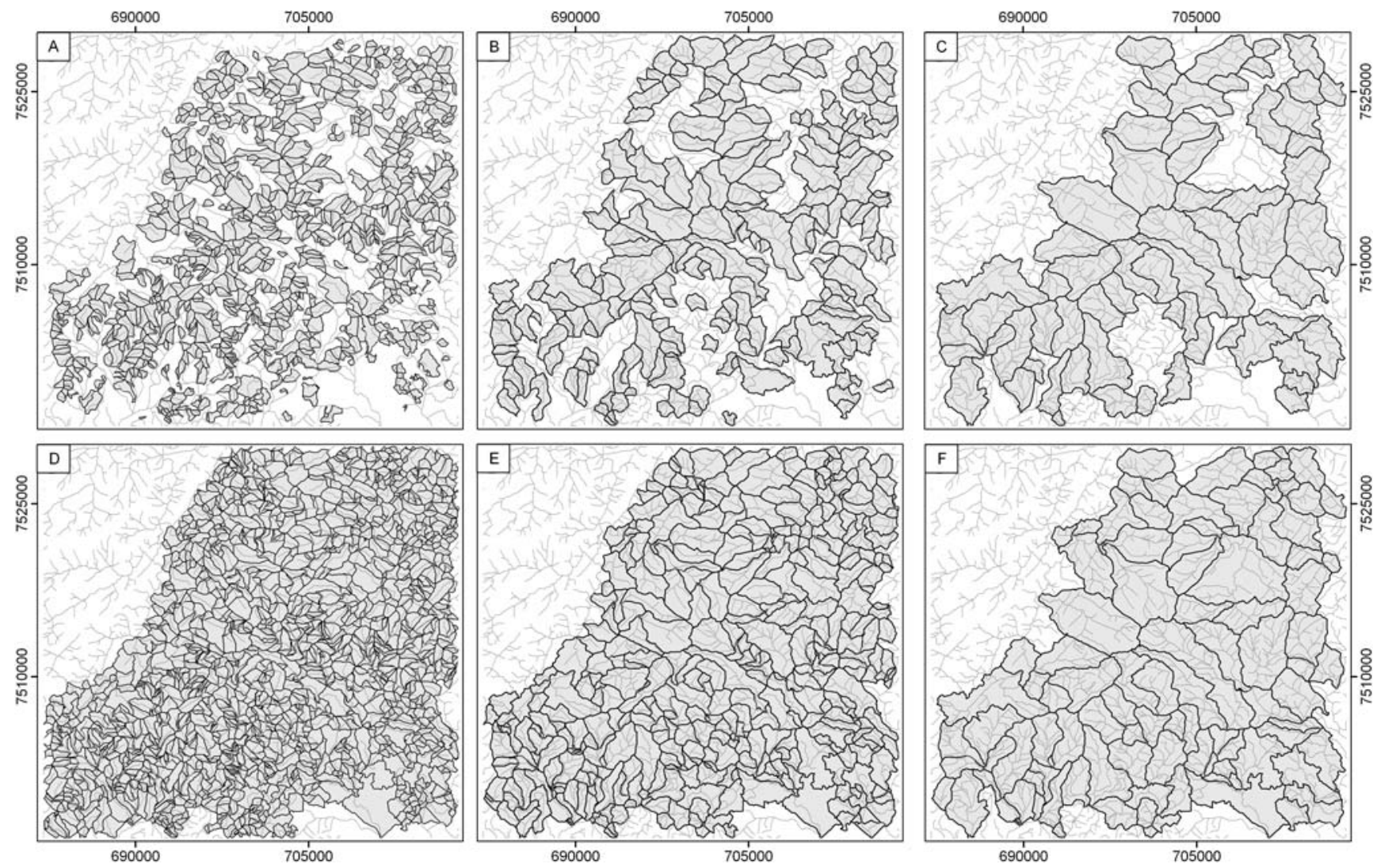

Figura 7 - Bacias de $1^{a}$ ordem (A); bacias de $2^{a}$ ordem (B); bacias de $3^{a}$ ordem (C); bacias de $1^{a}$ ordem mais os fragmentos (D); bacias de $2^{a}$ ordem mais os fragmentos $(E)$; bacias de $3^{a}$ ordem mais os fragmentos $(F)$.

e 3). Estes parâmetros salientam o desnível abrupto das bacias de drenagem posicionadas ao longo da escarpa (com desníveis que ultrapassam $2.000 \mathrm{~m}$ ). Considerando as bacias de $3^{\text {a }}$ ordem os desníveis mais acentuados ocorrem nas bacias do Rio Soberbo, Rio Bananal e Córrego Sossego. Essas bacias junto as Escarpas Serranas evoluem a partir de uma frente de dissecação de bloco falhado fortemente relacionado com os condicionantes estruturais provenientes das fraturas e falhas, onde ocorrem com freqüência os movimentos de massa.

Os parâmetros área e perímetro apresentam alta correlação entre si (Figura 10 e Tabelas 1, 2 e 3). No entanto, esses parâmetros apresentam mudanças significativas de padrões, quando se considera a presença ou não dos fragmentos de bacias, como também, as diferentes ordens fluviais. Pode-se observar nesses atributos, por exemplo, uma expressiva variação na localização dos valores máximos e mínimos nos diferentes conjuntos de dados.

O índice de circularidade não apresenta correlação com nenhum outro parâmetro (Figura 10 e Tabelas 1, 2 e 3). No entanto, observa-se um predomínio de bacias com baixa circularidade localizadas a SSE e direcionadas para o litoral, enquanto as bacias direcionadas para o continente apresentam formas mais circulares.

\subsection{Análise multivariada das bacias de drenagem}

\subsubsection{Análise de Componentes Principais (ACP)}

A ACP permitiu diminuir a redundância dos dados e destacar os atributos mais significativos. Esta técnica foi aplicada aos dados morfométricos por tipo de bacia $\left(1^{\mathrm{a}}, 2^{\mathrm{a}} \mathrm{e}\right.$ $3^{\mathrm{a}}$ ordem) com os respectivos fragmentos. Neste método a contribuição de cada componente é expressa pelos autovalores. As três primeiras componentes principais concentram as informações dos diferentes tipos de bacias hidrográficas existentes na área de estudo (Figura 11).

A contribuição de cada métrica (variável original) para uma nova variável (CP) é descrita pela matriz de autovetores. Para os diferentes arranjos analisados os atributos de maior influência se mantiveram iguais para as três primeiras CPs. Este fato demonstra que as contribuições dos atributos morfométricos se mantiveram constantes sendo independentes da ordem fluvial ou da presença dos fragmentos.

A primeira CP nos diferentes arranjos analisados é mais influenciada pelos atributos de altitude média, máxima e mínima. Os resultados provenientes do processamento com 
Oliveira, S.N. et al.

\begin{tabular}{|l|r|r|r|r|r|r|r|r|r|}
\hline \multicolumn{7}{|c|}{ Tabela 1 - Matriz de correlação dos parâmetros morfométricos para as bacias de ${ }^{\text {a }}$ ordem } \\
\hline & Mínimo & Máximo & \multicolumn{1}{|c|}{ Média } & Amplitude & Desv. Padrão & Decl. Média & Perímetro & Área & \multicolumn{1}{c|}{ IC } \\
\hline Mínimo & $\mathbf{1 . 0 0}$ & $\mathbf{0 . 9 1}$ & $\mathbf{0 . 9 8}$ & 0.29 & 0.29 & 0.45 & -0.03 & 0.00 & 0.17 \\
\hline Máximo & $\mathbf{0 . 9 1}$ & $\mathbf{1 . 0 0}$ & $\mathbf{0 . 9 7}$ & 0.65 & 0.64 & 0.68 & 0.15 & 0.13 & 0.12 \\
\hline Média & $\mathbf{0 . 9 8}$ & $\mathbf{0 . 9 7}$ & $\mathbf{1 . 0 0}$ & 0.47 & 0.47 & 0.59 & 0.04 & 0.05 & 0.16 \\
\hline Amplitude & 0.29 & 0.65 & 0.47 & $\mathbf{1 . 0 0}$ & $\mathbf{0 . 9 7}$ & $\mathbf{0 . 7 6}$ & 0.42 & 0.29 & -0.02 \\
\hline Desv.Padrão & 0.29 & 0.64 & 0.47 & $\mathbf{0 . 9 7}$ & $\mathbf{1 . 0 0}$ & $\mathbf{0 . 8 0}$ & 0.36 & 0.24 & -0.01 \\
\hline Decl. Média & 0.45 & 0.68 & 0.59 & $\mathbf{0 . 7 6}$ & $\mathbf{0 . 8 0}$ & $\mathbf{1 . 0 0}$ & 0.06 & 0.01 & 0.16 \\
\hline Perímetro & -0.03 & 0.15 & 0.04 & 0.42 & 0.36 & 0.06 & $\mathbf{1 . 0 0}$ & $\mathbf{0 . 9 1}$ & -0.12 \\
\hline Área & 0.00 & 0.13 & 0.05 & 0.29 & 0.24 & 0.01 & $\mathbf{0 . 9 1}$ & $\mathbf{1 . 0 0}$ & 0.05 \\
\hline IC & 0.17 & 0.12 & 0.16 & -0.02 & -0.01 & 0.16 & -0.12 & 0.05 & 1.00 \\
\hline
\end{tabular}

\begin{tabular}{|l|r|r|r|r|r|r|r|r|r|}
\hline \multicolumn{7}{|c|}{ Tabela 2 } & Matriz de correlação dos parâmetros morfométricos para as bacias de $2^{\text {a }}$ ordem \\
\hline & Mínimo & Máximo & \multicolumn{1}{c|}{ Média } & Amplitude & Desv. Padrão & Decl. Média & Perímetro & Área & \multicolumn{1}{c|}{ IC } \\
\hline Mínimo & $\mathbf{1 . 0 0}$ & $\mathbf{0 . 8 1}$ & $\mathbf{0 . 9 4}$ & 0.25 & 0.23 & 0.46 & 0.06 & 0.12 & 0.17 \\
\hline Máximo & $\mathbf{0 . 8 1}$ & $\mathbf{1 . 0 0}$ & $\mathbf{0 . 9 5}$ & $\mathbf{0 . 7 6}$ & $\mathbf{0 . 7 4}$ & $\mathbf{0 . 7 6}$ & 0.38 & 0.40 & 0.06 \\
\hline Média & $\mathbf{0 . 9 4}$ & $\mathbf{0 . 9 5}$ & $\mathbf{1 . 0 0}$ & 0.53 & 0.52 & 0.65 & 0.20 & 0.24 & 0.13 \\
\hline Amplitude & 0.25 & $\mathbf{0 . 7 6}$ & 0.53 & $\mathbf{1 . 0 0}$ & $\mathbf{0 . 9 7}$ & $\mathbf{0 . 7 6}$ & 0.56 & 0.53 & -0.09 \\
\hline Desv. Padrão & 0.23 & $\mathbf{0 . 7 4}$ & 0.52 & $\mathbf{0 . 9 7}$ & $\mathbf{1 . 0 0}$ & $\mathbf{0 . 7 7}$ & 0.51 & 0.48 & -0.07 \\
\hline Decl. Média & 0.46 & $\mathbf{0 . 7 6}$ & 0.65 & $\mathbf{0 . 7 6}$ & $\mathbf{0 . 7 7}$ & $\mathbf{1 . 0 0}$ & 0.19 & 0.19 & 0.18 \\
\hline Perímetro & 0.06 & 0.38 & 0.20 & 0.56 & 0.51 & 0.19 & $\mathbf{1 . 0 0}$ & $\mathbf{0 . 9 4}$ & -0.30 \\
\hline Área & 0.12 & 0.40 & 0.24 & 0.53 & 0.48 & 0.19 & $\mathbf{0 . 9 4}$ & $\mathbf{1 . 0 0}$ & -0.13 \\
\hline IC & 0.17 & 0.06 & 0.13 & -0.09 & -0.07 & 0.18 & -0.30 & -0.13 & 1.00 \\
\hline
\end{tabular}

Tabela 3 - Matriz de correlação dos parâmetros morfométricos para as bacias de 3a ordem

\begin{tabular}{|l|r|r|r|r|r|r|r|r|r|}
\hline & Mínimo & Máximo & \multicolumn{1}{c|}{ Média } & Amplitude & Desv.Padrão & Decl. Média & Perímetro & \multicolumn{1}{l}{ Área } & \multicolumn{1}{l|}{ IC } \\
\hline Mínimo & $\mathbf{1 . 0 0}$ & $\mathbf{0 . 6 5}$ & $\mathbf{0 . 8 9}$ & 0.11 & 0.04 & 0.48 & 0.00 & 0.12 & 0.32 \\
\hline Máximo & $\mathbf{0 . 6 5}$ & $\mathbf{1 . 0 0}$ & $\mathbf{0 . 9 0}$ & $\mathbf{0 . 8 3}$ & $\mathbf{0 . 7 6}$ & $\mathbf{0 . 8 4}$ & 0.43 & 0.53 & 0.12 \\
\hline Média & $\mathbf{0 . 8 9}$ & $\mathbf{0 . 9 0}$ & $\mathbf{1 . 0 0}$ & 0.52 & 0.47 & 0.73 & 0.20 & 0.32 & 0.26 \\
\hline Amplitude & 0.11 & $\mathbf{0 . 8 3}$ & 0.52 & $\mathbf{1 . 0 0}$ & $\mathbf{0 . 9 6}$ & $\mathbf{0 . 7 5}$ & 0.57 & 0.60 & -0.08 \\
\hline Desv. Padrão & 0.04 & $\mathbf{0 . 7 6}$ & 0.47 & $\mathbf{0 . 9 6}$ & $\mathbf{1 . 0 0}$ & $\mathbf{0 . 6 9}$ & 0.52 & 0.54 & -0.10 \\
\hline Decl. Média & 0.48 & $\mathbf{0 . 8 4}$ & 0.73 & $\mathbf{0 . 7 5}$ & $\mathbf{0 . 6 9}$ & $\mathbf{1 . 0 0}$ & 0.21 & 0.29 & 0.33 \\
\hline Perímetro & 0.00 & 0.43 & 0.20 & 0.57 & 0.52 & 0.21 & $\mathbf{1 . 0 0}$ & $\mathbf{0 . 9 2}$ & -0.57 \\
\hline Área & 0.12 & 0.53 & 0.32 & 0.60 & 0.54 & 0.29 & $\mathbf{0 . 9 2}$ & $\mathbf{1 . 0 0}$ & -0.32 \\
\hline IC & 0.32 & 0.12 & 0.26 & -0.08 & -0.10 & 0.33 & -0.57 & -0.32 & 1.00 \\
\hline
\end{tabular}

fragmentados ou não se mostram equivalentes. Destacam-se os comportamentos distintos entre as porções NNW e SSE da escarpa da Serra dos Órgãos. À medida que aumenta a ordem das bacias é realçada a zona central onde ocorrem as maiores declividades do relevo (Figura 12).

Os autovetores das segundas CPs nas diferentes ordens fluviais demonstram maior influência dos fatores relativos aos atributos perímetro, área, índice de circularidade e altura mínima. Apesar dos padrões não serem tão distintos pode-se também observar arranjos espaciais distintos na parte central e a nordeste da área (Figura 12).
A terceira CP, nos diferentes arranjos analisados, apresenta uma forte influência dos parâmetros relativos ao gradiente topográfico (desvio padrão da altimetria, amplitude topográfica e média da declividade). Nesta componente as bacias localizadas na escarpa foram individualizadas, conforme destacadas na porção SSE da Figura 12.

\subsection{2 - Análise de Grupos}

O emprego da técnica de análise de grupos permitiu agrupar bacias com parâmetros semelhantes vinculados às características geomorfológicas da área. 
Delimitação automática de bacias de drenagens e análise multivariada de atributos...
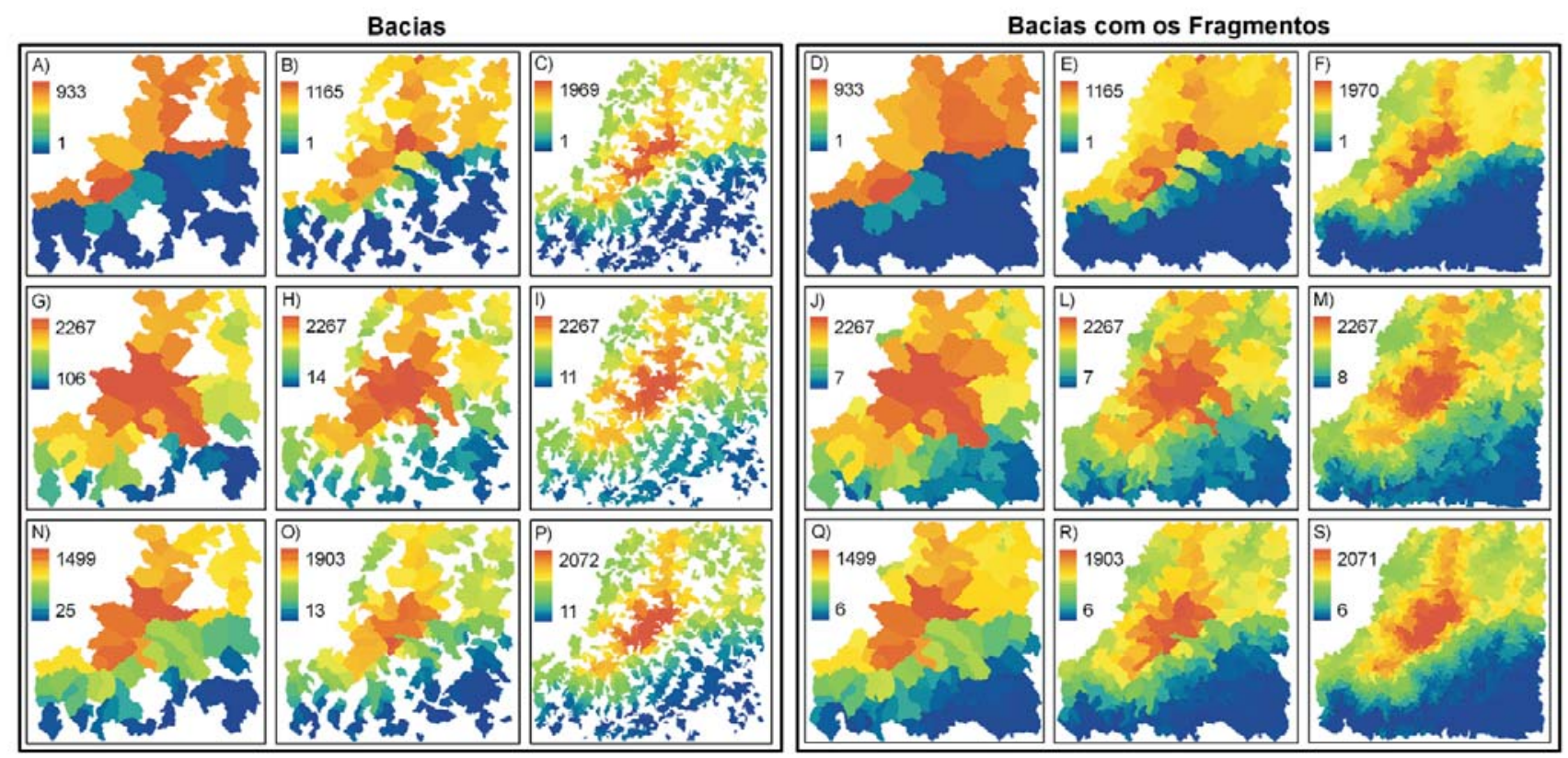

Figura 8 - Altitude mínima em metros para as bacias de $3^{a}$ ordem (A), $2^{a}$ ordem (B) e $1^{a}$ ordem (C). Altitude mínima em metros para as bacias de $3^{a}$ ordem mais fragmentos $(D), 2^{a}$ ordem mais fragmentos $(E)$ e $1^{a}$ ordem mais fragmentos $(F)$. Altitude máxima em metros para as bacias de $3^{a}$ ordem $(G), 2^{a}$ ordem $(H)$ e $1^{a}$ ordem (I). Altitude máxima em metros para as bacias de $3^{a}$ ordem mais fragmentos $(\mathrm{J}), 2^{a}$ ordem mais fragmentos $(L)$ e $1^{a}$ ordem mais fragmentos $(M)$. Altitude média em metros para as bacias de $3^{a}$ ordem $(N), 2^{a}$ ordem $(O)$ e $1^{a}$ ordem $(P)$. Altitude média em metros para as bacias de $3^{a}$ ordem mais fragmentos $(Q), 2^{a}$ ordem mais fragmentos $(R)$ e $1^{a}$ ordem mais fragmentos $(S)$.
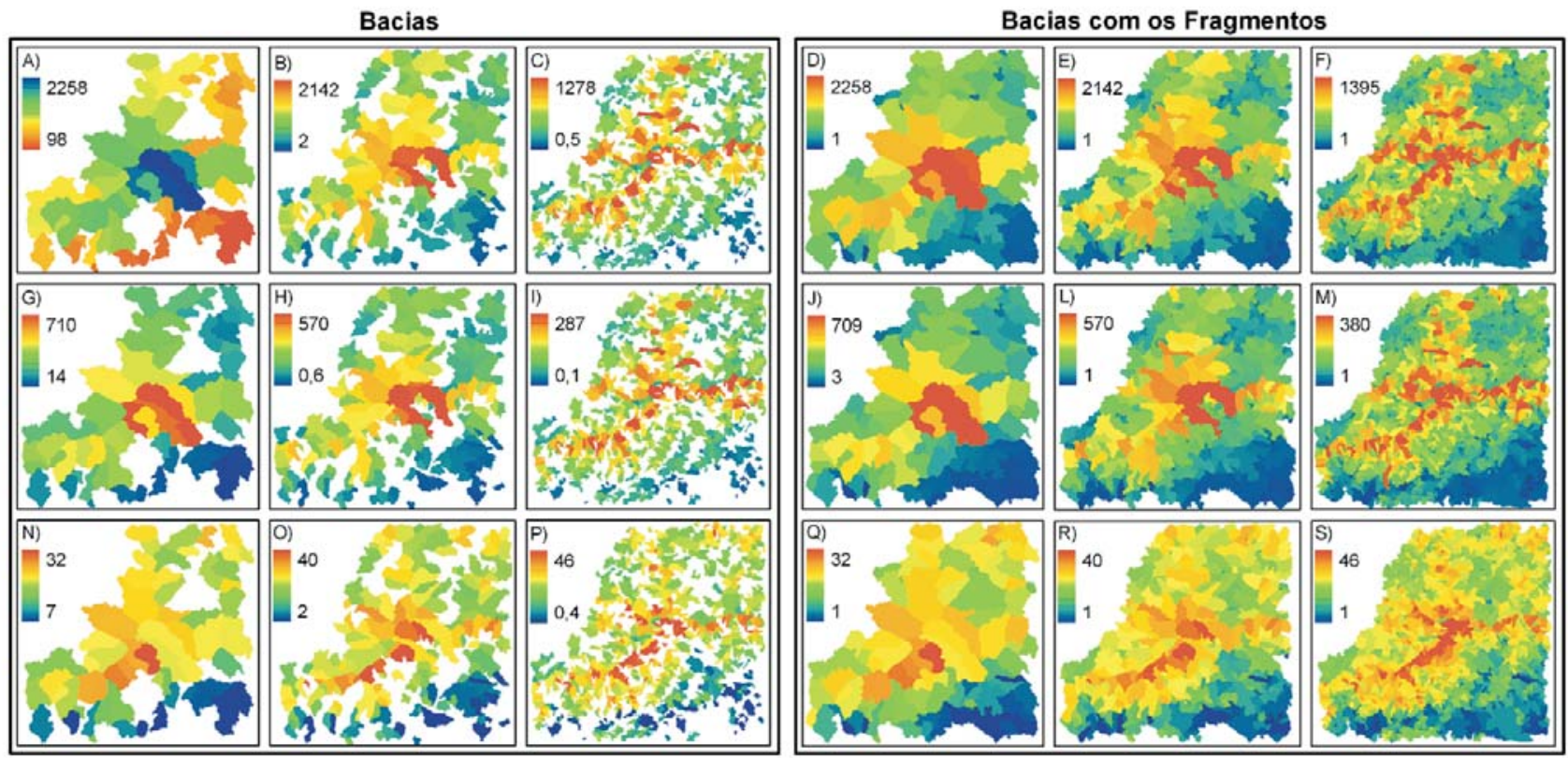

Figura 9 - Amplitude topográfica em metros para as bacias de $3^{a}$ ordem (A), $2^{a}$ ordem (B) e $1^{a}$ ordem (C). Amplitude topográfica em metros para as bacias de $3^{a}$ ordem mais fragmentos $(D), 2^{a}$ ordem mais fragmentos $(E)$ e $1^{a}$ ordem mais fragmentos (F). Desvio padrão altimétrico para as bacias de $3^{a}$ ordem $(G), 2^{a}$ ordem $(H)$ e $1^{a}$ ordem (I). Desvio padrão altimétrico para as bacias de $3^{a}$ ordem mais fragmentos $(J), 2^{a}$ ordem mais fragmentos $(L)$ e $1^{a}$ ordem mais fragmentos $(M)$. Declividade média em graus $\left(^{\circ}\right)$ para as bacias de $3^{a}$ ordem $(N), 2^{a}$ ordem $(O)$ e $1^{a}$ ordem (P). Declividade média para as bacias de $3^{a}$ ordem mais fragmentos $(Q), 2^{a}$ ordem mais fragmentos $(R)$ e $1^{a}$ ordem mais fragmentos (S). 

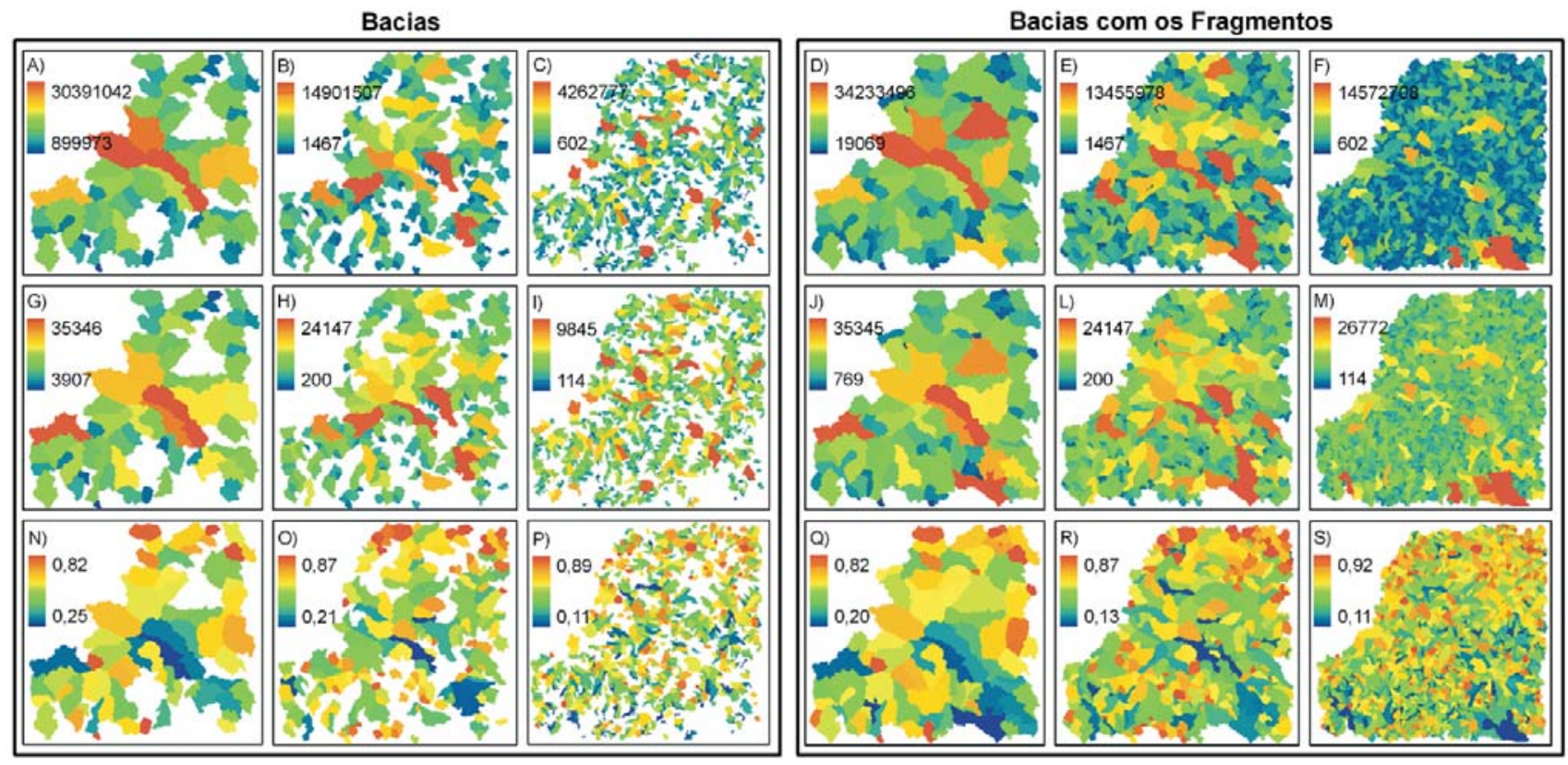

Figura 10 - Área em metros quadrados das bacias de $3^{a}$ ordem (A), $2^{a}$ ordem (B) e $1^{a}$ ordem (C). Área em metros quadrados das bacias de $3^{a}$ ordem mais fragmentos (D), $2^{a}$ ordem mais fragmentos $(E)$ e $1^{a}$ ordem mais fragmentos $(F)$. Perímetro em metros das bacias de $3^{a}$ ordem (G), $2^{a}$ ordem (H), $1^{a}$ ordem (I). Perímetro em metros das bacias de $3^{a}$ ordem mais fragmentos $(\mathrm{J}), 2^{a}$ ordem mais fragmentos $(L)$ e $1^{a}$ ordem mais fragmentos $(M)$. Índice de Circularidade para as bacias de $3^{a}$ ordem $(N), 2^{a}$ ordem $(O)$ e $1^{a}$ ordem $(P)$. Índice de Circularidade para as bacias de $3^{a}$ ordem mais fragmentos $(Q), 2^{a}$ ordem mais fragmentos $(R)$ e $1^{a}$ ordem mais fragmentos $(S)$.
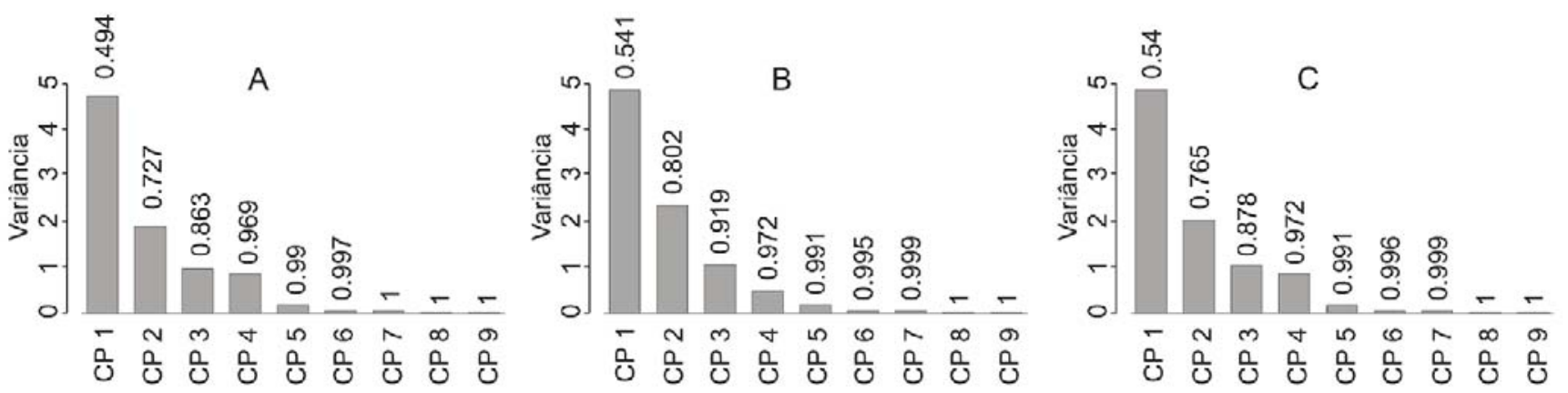

Figura 11 - Importância relativa das componentes principais para as bacias e fragmentos de: 1 a ordem (A), $2^{a}$ ordem (B) e $3 a$ ordem (C).

Os agrupamentos das bacias de terceira ordem fluvial permitiram identificar as seguintes unidades: áreas de baixada (classe 1 para as bacias sem fragmentos e classes 1 e 2 para as bacias com fragmentos), escarpa (classes 3, 4 e 5 para os dois tipos de bacias) e as áreas de planalto (classes 2, 6 e 7 para as bacias sem fragmentos e classes 6 e 7 para as bacias com fragmentos) (Figuras 13a e 13b).

Os agrupamentos das bacias de $2^{\mathrm{a}}$ ordem permitiram um detalhamento do padrão descrito pelas bacias de $3^{\mathrm{a}}$ ordem. Os agrupamentos individualizados para a $2^{\mathrm{a}}$ ordem fo- ram os seguintes: áreas de baixada (classe 1 para as bacias sem fragmentos e classes 1 e 2 para as bacias com fragmentos), escarpa (classes 3, 4 e 5 para os dois padrões) e as áreas de planaltos (6 e 7 para os dois padrões) (Figura 13c e 13d).

Na classificação das bacias de $1^{\text {a }}$ ordem observa-se um maior detalhamento sendo possível individualizar as seguintes classes: áreas de baixada (classes 1 e 2 para os dois tipos de bacias), escarpa (classes 4 e 5 para os dois tipos de bacias), topo (classe 3 para os dois tipos de bacias), vertentes de planalto (classes 6 e 7 para os dois tipos de bacias) (Figuras 13e e 13f). 

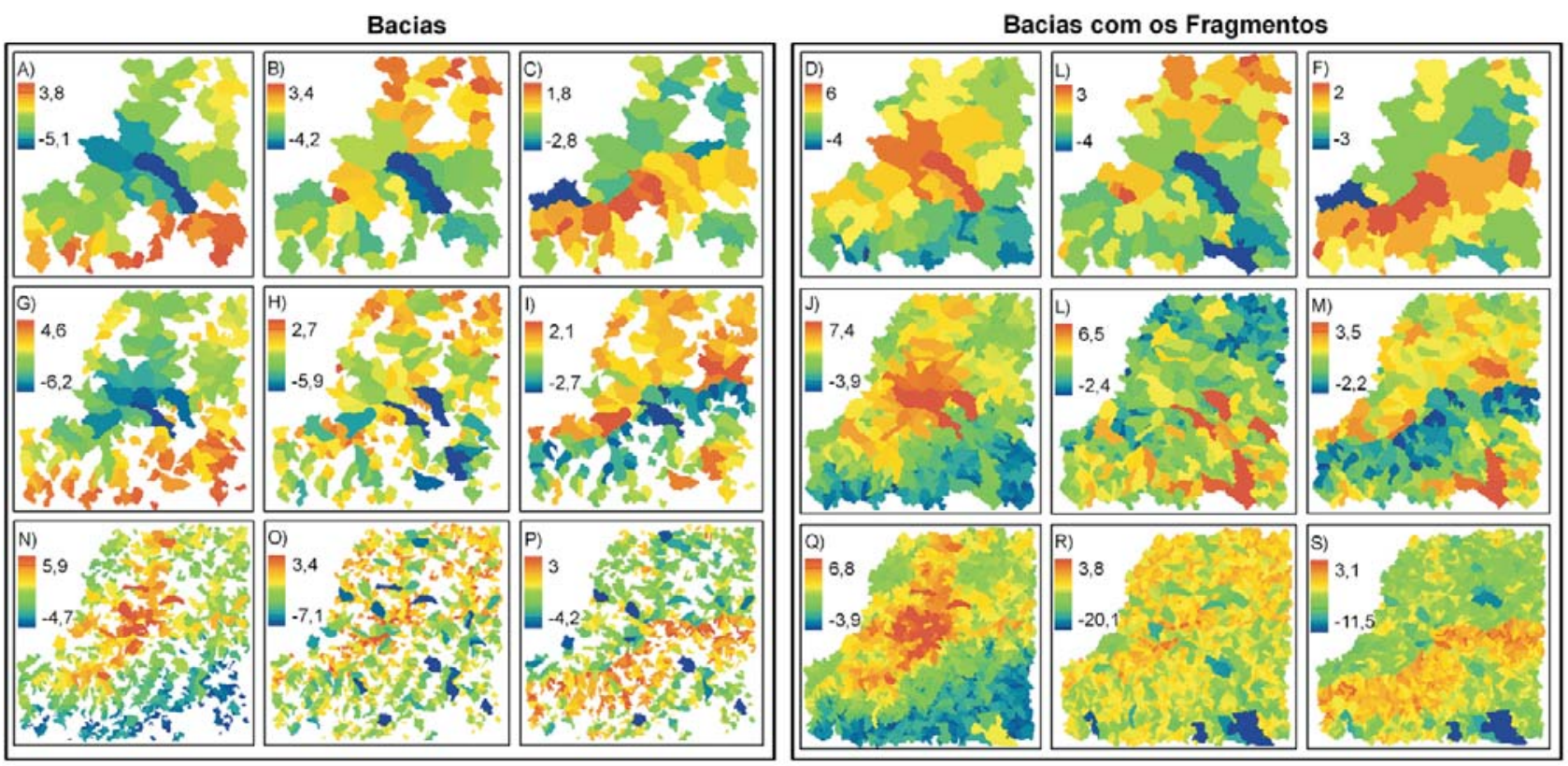

Figura 12 - ACP para as bacias de $3^{a}$ ordem: $1^{a} C P(A) ; 2^{a} C P(B) ; 3^{a} C P(C)$. ACP para as bacias de $3^{a}$ ordem mais fragmentos: $1^{a} C P(D)$; $2^{a} C P(E) ; 3^{a} C P(F)$. ACP para as bacias de $2^{a}$ ordem: $1^{a} C P(G) ; 2^{a} C P(H) ; 3^{a} C P(I)$. ACP para as bacias de $2^{a}$ ordem mais fragmentos: $1^{a} \mathrm{CP}(\mathrm{J}) ; 2^{a} \mathrm{CP}(\mathrm{L}) ; 3^{a} \mathrm{CP}(\mathrm{M})$. ACP para as bacias de $1^{a}$ ordem: $1^{a} \mathrm{CP}(\mathrm{N}) ; 2^{a} \mathrm{CP}(\mathrm{O}) ; 3^{a} \mathrm{CP}(\mathrm{P})$. ACP para as bacias de $1^{a}$ ordem mais fragmentos: $1^{a} C P(Q) ; 2^{a} C P(R) ; 3^{a} C P(S)$.

\section{Conclusão}

A metodologia empregada para obtenção de um MDE hidrologicamente corrigido permitiu a delimitação automática das bacias de drenagem. Para tanto, foram utilizados métodos adequados de interpolação (TOPOGRID) e de procedimentos para a correção de erros como preenchimento das depressões artificiais e introdução de informações sobre as localizações de rede de drenagem e dos lagos.

A obtenção dos dados morfométricos das bacias de drenagem permitiu caracterizá-las e agrupá-las em padrões espaciais. O emprego de métodos estatísticos multivariados permitiu identificar grupos de bacias com comportamento e dinâmicas evolutivas similares. A análise realizada a partir da distribuição das bacias de ordens hierárquicas diferentes permite uma abordagem escalar.

Os dados morfométricos de bacia analisados permitiram distinguir comportamentos distintos entre as bacias que drenam em direção ao continente e em direção ao litoral, caracterizando ambientes diferenciados. Enquanto as bacias interioranas são caracterizadas por ambientes mais suavizados, as bacias voltadas para o litoral possuem escarpas íngremes resultando em ambientes mais dinâmicos. A análise realizada também permitiu detalhar o topo e a escarpa da Serra dos Órgãos.
Como objetivo de compartimentar ambientes o emprego conjunto das bacias hidrográficas mais os fragmentos torna-se adequado. No entanto, para o propósito de estudos hidrológicos deve-se ter maior precaução limitando-se às bacias hidrográficas (sem os fragmentos).

A metodologia desenvolvida com base na utilização de métodos computacionais para o tratamento de informações de bacias de drenagem permite a obtenção de informações de forma mais rápida, eficiente e padronizada. Os resultados obtidos indicam a sua viabilidade de aplicação em outras áreas.

\section{Agradecimentos}

Os autores agradecem aos seguintes financiadores: CAPES pelo financiamento da bolsa de mestrado do autor Sandro Nunes de Oliveira; ao CNPq pelo financiamento das bolsas de pesquisa aos autores Osmar Abílio de Carvalho Júnior e Renato Fontes Guimarães, ao MMA que custeou o trabalho de campo e ao Parque Nacional da Serra dos Órgãos que forneceu importante apoio logístico. Em especial os autores agradecem a equipe do PREVFOGO do PARNASO que apoiou o trabalho de campo ajudando no aporte logístico de locomoção e mapeamento da área. Além disso, os autores agradecem aos membros do Laboratório de Sistemas de Informações Espaciais (LSIE) da UnB pelas críticas e sugestões realizadas durante a elaboração do artigo. 

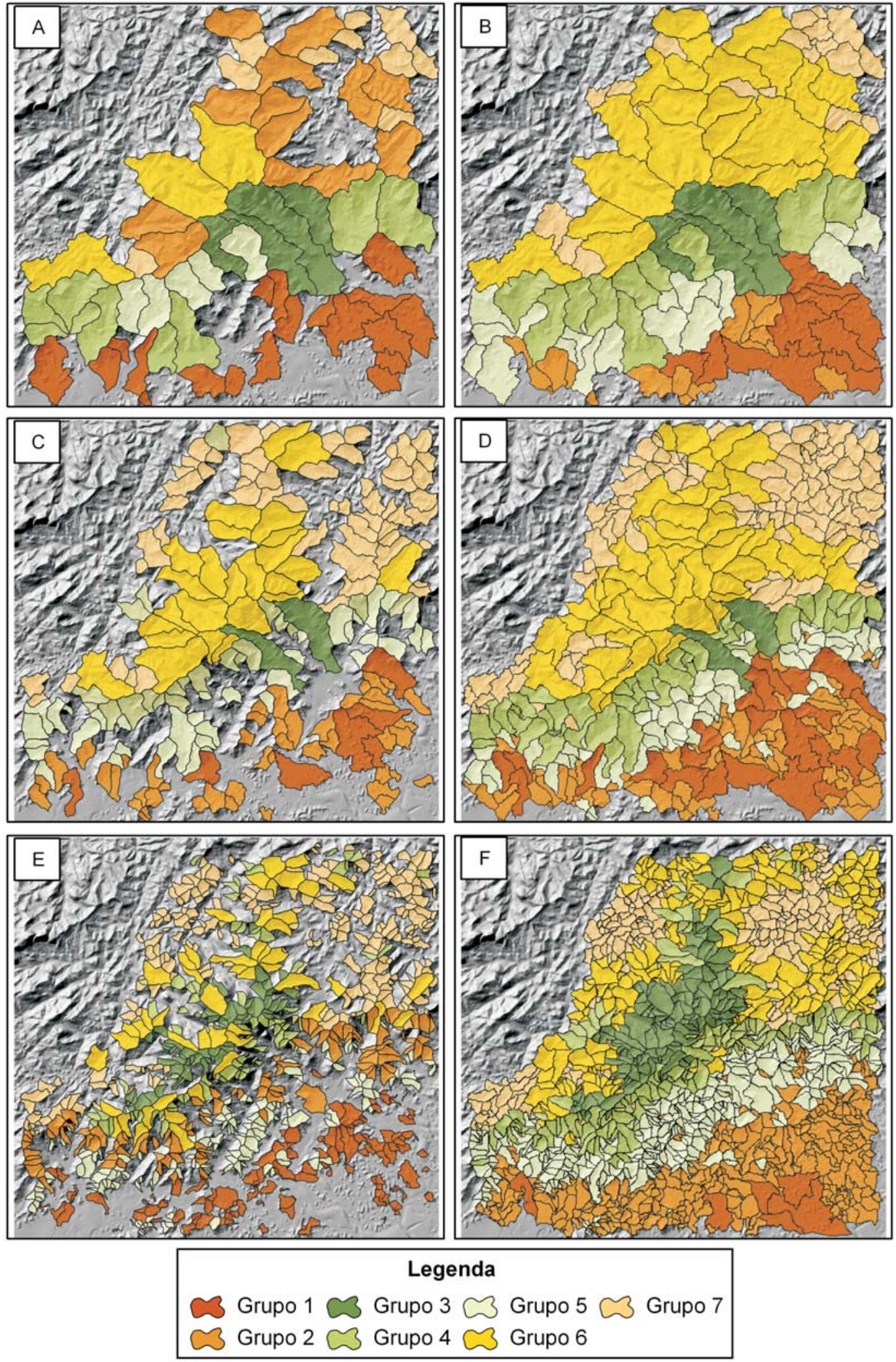

Figura 13 - Classificação pelo Método K-Médias para as bacias de $3^{a}$ ordem (A); bacias de $3^{a}$ ordem mais fragmentos (B); bacias de $2^{a}$ ordem $(C)$; bacias de $2^{a}$ ordem mais fragmentos $(D)$; bacias de $1^{a}$ ordem $(E)$; bacias de $1^{a}$ ordem mais fragmentos $(F)$. 
Delimitação automática de bacias de drenagens e análise multivariada de atributos...

\section{Referências Bibliográficas}

Alonso, M.T.A. (1977) Vegetação. In: Goldenberg, C. (ed.). Geografia do Brasil: Região Sudeste. Rio de Janeiro: IBGE, 3: 91-118.

Band, L.E. (1986) Topographic partition of watersheds with digital elevation models. Water Resources Research, 22 (1): 15-24.

Band, L.E. (1989) A terrain-based watershed information system. Hydrological Processes, 4: 151-162.

Brasil. Ministério das Minas e Energia. Projeto Radambrasil. (1983). Folhas SF. 23/24 Rio de Janeiro/Vitória. Geologia. Rio de Janeiro: DNPM, v. 32, p. 56-66.

Brasil. (1997) Lei Federal $n^{\circ}$ 9.433, de 08 de janeiro de 1997. Diário Oficial da União. Brasília, Imprensa Oficial, 09 de janeiro de 1997.

Cardoso, C.A.; Dias, H.C.T.; Soares, C.P.B. \& Martins, S.V. (2006) Caracterização morfométrica da bacia hidrográfica do rio Debossan, Nova Friburgo, RJ. Revista Árvore, 30 (2): 241-248.

Chomwicz, J.; Lchoku, C.; Riazanoff, S.; Kim, Y.J. \& Cervelle, B. (1992) A combined algorithm for automated drainage network extraction. Water Resources Research, 28 (5): 1293-1302.

Christofoletti, A. (1980). Geomorfologia. 2a ed. São Paulo: Edgard Blücher. 188p.

Costa-Cabral, M.C. \& Burges, S.J. (1994) Digital elevation model networks (DEMON): A model of flow over hillslopes for computation of contributing and dispersal areas. Water Resources Research, 30 (6): 1681-1692.

Demattê; J.A.M. \& Demétrio, V.A. (1995) Fotointerpretação de padrões de drenagem de bacias hidrográficas na caracterização de solos desenvolvidos de rochas eruptivas básicas no estado do Paraná. Scientia Agricola, 52 (3):567-577.

Desmet, P.J.J. \& Govers, G. (1996) Comparison of routing algorithms for digital elevation models and their implications for predicting ephemeral gullies. International Journal of Geographical Information Systems, 10 (3): 311-331.

ESRI. (1998) Understanding GIS: the ArcInfo method. Redlands, CA, USA: ESRI Press. 680 p.

Freeman, T.G. (1991) Calculating catchment area with divergent flow based on a regular grid. Computers and Geosciences, 17: 413- 422.
Garbrecht, J. \& Martz, L.W. (1997) The assignment of drainage direction over flat surfaces in raster digital elevation models. Journal of Hydrology, 193: 204213.

Grimaldi, S.; Nardi, F.; Benedetto F.; Istanbulluoglu, E. \& Brás, R.L. (2007) A physically-based method for removing pits in digital elevation models. Advances in Water Resources, 30: 2151-2158.

Hadley, R.F. \& Schumm, S.A. (1961) Sediment sources and drainage basin characteristics in Upper Cheyenne River basin. U.S. Geol. Survey Water-Supply Paper 1531-B, p. 137-197.

Hair Jr., J.F.; Anderson, R.E. \& Tatham, R.L. (1987) Multivariate Data Analysis, 2.ed. New York: Macmillan Publish Company. 449 p.

Horton, R.E. (1945) Erosinal development of streams and their drainage basins: hidrophysical approach to quantitative morphology. Bulletin of the Geological Society of America, 56: 275-370.

Hutchinson, M.F. (1989) A new procedure for gridding elevation and stream line data with automatic removal of spurious pits. Journal of Hydrology, 106: 211-232.

Instituto Brasileiro de Geografia e Estatística - IBGE. (1979) Carta Topográfica Digital 1/50.000, Folha Itaboraí. SF-23-Z-B-V-1, MI2746.1.

Instituto Brasileiro de Geografia e Estatística - IBGE. (1983) Carta Topográfica Digital 1/50.000, Folha Teresópolis. SF-23-Z-B-II-3, MI2716.3.

Instituto Brasileiro de Geografia e Estatística - IBGE. (1979) Carta Topográfica Digital 1/50.000, Folha Itaipava. SF-23-Z-B-I-4, MI2715-4.

Instituto Brasileiro de Geografia e Estatística - IBGE. (1979) Carta Topográfica Digital 1/50.000, Folha Petrópolis. SF-23-Z-B-IV-2, MI2745.2.

Jenson, S.K. \& Domingue, J.O. (1987) Extracting topographic structure from digital elevation data for geographical information system analysis. Photogrammetric Engineering \& Remote Sensing, 54: 1593-1600.

Langbein, W.B. \& Leopold, L.B. (1964) Quasi-equilibrium states in channel morphology. American Journal of Science, 262: 782-794.

Langbein, W.B. (1964) Geometry of river channels. J. Hydraul. Div. Am. Soc. Civ. Eng., 90 (HY2), 301-312. 
Lanna, A.E.L. (1995) Gerenciamento de Bacia Hidrográfica Aspectos Conceituais e Metodológicos. Brasília: IBAMA. 170 p.

Lindsay, J.B. \& Creed, I.F. (2005) Sensitivity of digital landscapes to artifact depressions in remotelysensed DEMs. Photogrammetric Engineering \& Remote Sensing, 71 (9): 1029-36.

Llamas, J. (1993) Hidrología General: principios y aplicaciones. Bilbao: Servicio Editorial de la Universidad del País Vasco. 627p.

Mackay, S.D. \& Band, L.E. (1998) Extraction and representation of nested catchment areas from digital elevation models in lake dominated topography. Water Resources Research, 34: 897901.

Mark, D.M. (1983) Relations Between field-surveyed channel networks and map-based geomorphometric measures, Inez, Kentucky. Annals of the Association of American Geographers, 73 (3): 358372.

Martinelli, G. (1989) Campos de altitude. Rio de Janeiro: Editora Index. $158 \mathrm{p}$.

Martz, L.W. \& de Jong, E. (1988) Catch: a Fortran program for measuring catchment area from digital elevation models. Computers and Geosciences, 14 (5): 627640.

Martz, L.W. \& Garbrecht, J. (1992) Numerical definition of drainage network and subcatchment areas from digital elevation models. Computers and Geosciences, 18 (6): 747-761.

Martz, L.W. \& Garbrecht, J. (1993) Automated extraction of drainage network and watershed data from digital elevation models. Journal of the American Water Resources Association, 29 (6): 901-908.

Martz, L.W. \& Garbrecht, J. (1995) Automated recognition of valley lines and drainage networks from grid digital elevation models: a review and a new method comment. Journal of Hydrology, 167: 393-396.

Mather, P.M. \& Doornkamp, J.C. (1970) Multivariate Analysis in Geography with Particular Reference to Drainage-Basin Morphometry. Transactions of the Institute of British Geographers, 51:163-187.

Meis, M.R.M.; Miranda, L.H.G. \& Fernandes, N.F. (1982) Desnivelamento de altitude como parâmetro para a compartimentação do relevo: bacia do médiobaixo Paraíba do Sul. In: Congresso Brasileiro de Geologia (CBG), 32., Salvador (BA). Anais...
Salvador: Sociedade Brasileira de Geologia. 4: 14891509.

Mesa, L.M. (2006) Morphometric analysis of a subtropical Andean basin (Tucumán, Argentina). Environmental Geology, 50: 1235-1242.

Miller, V.C. (1953) A quantitative geomorphic study of drainage basin characteristics in the Clinch Mountain area, Virginia and Tennessee. Technical report, 3, Office of Naval Research. Department of Geology, Columbia University, New York.

Montgomery, D.R. \& Dietrich,W.E. (1992) Channel initiation and the problem of landscape scale. Science, 255: 826-830.

Morris, D.G. \& Heerdegen, R.G. (1988) Automatically derived catchment boundaries and channel networks and their hydrological applications. Geomorphology, 1:131-141.

Nimer, E. (1977) Clima. In: Goldenberg, C. (ed.). Geografia do Brasil: Região Sudeste. Rio de Janeiro: IBGE, 3: 51-89.

O’Callaghan, J.F. \& Mark, D.M. (1984) The extraction of drainage networks from digital elevation data. Computer vision, graphics, and image processing, 28: 323-344.

Pinto, N.L.S.; Holtz, A.C.T. \& Martins, J.A. (1973) Hidrologia de superfície. 2 ed. São Paulo: Edgard Blucher. 179p.

Quinn, P.; Beven, K.; Chevallier, P. \& Planchon, O. (1991) The prediction of hillslope flow paths for distributed hydrological modeling using digital terrain models. Hydrological Processes, 5: 59-80.

Ramos, V.M., Guimarães, R.F., Redivo, A.L., Carvalho Júnior, O.A. de, Fernandes, N.F. \& Gomes, R.A.T. (2003) Avaliação de metodologias de determinação do cálculo de áreas de contribuição. Revista Brasileira de Geomorfologia, 4 (2): 41-49.

Reddy, G.P.O.; Maji, A.K. \& Gajbhiye K.S. (2004) Drainage morphometry and its influence on landform characteristics in a basaltic terrain, Central India a remote sensing and GIS approach. International Journal of Applied Earth Observation and Geoinformation, 6: 1-16.

Richards, J.A. (1986) Remote sensing digital images analysis: An introduction. Berlin: Springer-Verlag. 281p.

Rizzini, C.T. (1979) Tratado de fitogeografia do Brasil. São Paulo: Hucitec, 2 ed. 374 p. 
Delimitação automática de bacias de drenagens e análise multivariada de atributos...

Rodriguez-Iturbe, I.; Ijjasz-Vasquez, E. \& Bras, R.L. (1992a) Power law distributions of mass and energy in river basins. Water Resources Research, 28 (4): 10891093.

Rodriguez-Iturbe, I.; Rinaldo, A.; Rigon, R.; Bras, R.L.; Marani, A. \& Ijjasz-Vasquez, E. (1992b) Energy dissipation, runoff, and the three-dimensional structure of river basins. Water Resources Research, 28 (4): 10951103.

Silva, T.M. (2002) A Estruturação Geomorfológica do Planalto Atlântico no Estado do Rio de Janeiro. 265p. Tese (Doutorado em Geografia) Departamento de Geografia - IGEO/UFRJ, Rio de Janeiro.

Silva, T.M. (2003) A estruturação geomorfológica do Planalto Atlântico no Estado do Rio de Janeiro. In: Simpósio Brasileiro de Geografia Física Aplicada, 10., Rio de Janeiro. Anais do X SBGFA, Rio de Janeiro: UERJ. $11 \mathrm{p}$.

Silva, T.M. (2005) Mapeamento Geomorfológico do Estado do Rio de Janeiro com base na técnica desnivelamento altimétrico. In: Congresso Brasileiro de Cartografia (CBC), 22., Macaé (RJ). Anais... São Paulo: Sociedade Brasileira de Cartografia. CD-ROM.

Silveira, A.L.L. (2001) Ciclo Hidrológico e Bacia Hidrográfica. In: C.E.M. Tucci, (Org.). Hidrologia: Ciência e Aplicação. 2 ed. Porto Alegre: Editora da Universidade/UFRGS, ABRH. p. 35-51.

Smart, J.S. (1968) Statistical properties of stream lengths. Water Resources Research, 4 (5): 932-936.

Soille, P.; Vogt, J. \& Colombo, R. (2003) Carving and adaptive drainage enforcement of grid digital elevation models. Water Resources Research, 39 (12): 1366.

Souza, A.K.P.S. \& Batista, G.T. (2007) Caracterização fisiográfica da bacia hidrográfica do Alto Rio
Jamanxim, Pará, Brasil. Revista Ambiente e Água, 2 (2): 69-87.

Strahler, A.N. (1952) Hypsometric (area-altitude) analysis and erosional topography. Bulletin of the Geological Society of America, 63 (10):1117-1142.

Strahler, A.N. (1964) Quantitative geomorphology of drainage basins and channel networks. Section 4-2. In: Ven te Chow (ed.). Handbook of applied hydrology. New York: McGraw-Hill. p. 4-55.

Tarboton, D.G. (1997) A new method for the determination of flow directions and upslope areas in grid digital elevation models. Water Resources Research, 33 (2): 309-319.

Tarboton, D.G. (2005) Terrain Analysis Using Digital Elevation Models (TauDEM). http:// hydrology.neng.usu.edu/taudem/. Acesso em 05/ 02/2008.

Tianqi, A.; Takeuchi, K.; Ishidaira, H.; Yoshitani, J. \& Fukami, K. (2003) Development and application of a new algorithm for automated pit removal for grid DEMs. Hydrological Sciences Journal, 48 (6):985-997.

Tribe, A. (1992) Automated recognition of valley lines and drainage networks from grid digital elevation models: A review and a new method. Journal of Hydrology, 139: 263-293.

Turcotte, R.; Fortin, J.P.; Rousseau, A.N.; Massicotte, S. \& Villeneuve, J.P. (2001) Determination of the drainage structure of a watershed using a digital elevation model and a digital river and lake network. Journal of Hidrology, 240: 225-242.

Villela, S.M.; \& Mattos, A. (1975) Hidrologia Aplicada. São Paulo: McGraw-Hill. 245p.

Vogt, J.V.; Colombo, R. \& Bertolo, F. (2003) Deriving drainage networks and catchment boundaries: a new methodology combining digital elevation data and environmental characteristics. Geomorphology, 53: 281-298. 